\title{
Análisis de las estructuras emergentes del castillo de La Peña, cabeza de la encomienda calatrava de Martos (Jaén)
}

\section{Analysis of the standing structures of the Castle of The Rock, headquarter of the command of the Order of Calatrava in Martos (Jaen)}

\author{
Luis José García-Pulido \\ Universidad de Málaga / Laboratorio de Arqueología y Arquitectura de la Ciudad (LAAC) \\ Julio Navarro Palazón² \\ CSIC, Escuela de Estudios Árabes de Granada / Laboratorio de Arqueología y Arquitectura de la Ciudad (LAAC) \\ Fernando Ortega Camacho ${ }^{3}$ \\ Escuela Superior de Arte y Diseño de Andalucía, Granada
}

\section{RESUMEN}

En este artículo se aborda el análisis de los restos conservados del castillo de La Peña o fortaleza Alta de Martos (Jaén), importante yacimiento arqueológico que presenta estructuras emergentes de envergadura. Constituyó el castillo y sede principal del maestre de la Orden de Calatrava en la encomienda de Martos, territorio fronterizo con el reino nazarí de Granada entre los siglos XIII y XV, hasta que esta fortaleza fue abandonada en el siglo XVI. Además de la revisión crítica de la documentación existente sobre este singular ejemplo de arquitectura defensiva medieval, para realizar este análisis ha resultado fundamental el trabajo de campo y la elaboración de la planimetría completa y actualizada de las estructuras conservadas. Los resultados alcanzados en esta investigación arqueológica suponen un avance importante en el conocimiento de este Bien Patrimonial, y aportan nuevos datos que por ahora eran desconocidos o no se habían planteado. La documentación generada constituye la base para las intervenciones de restauración científica en este yacimiento.

Palabras clave: Técnicas constructivas; Fortaleza; Poliorcética; Frontera castellano-nazarí; Andalucía; Baja Edad Media; Arqueología.

\begin{abstract}
This paper is devoted to the analysis of the preserved remains of the castillo de La Peña or fortaleza Alta de Martos (Jaén), an important archaeological site with substantial standing structures. It was the main castle and headquarters of the master of the Military Order of Calatrava at the Command of Martos. Until its abandonment in the sixteenth century, this stronghold was an important Christian spot in the border territory contrary to the Nasrid kingdom of Granada between the thirteenth and fifteenth centuries. Besides the critical review of the existing documentation on this outstanding example of defensive medieval architecture, the fieldwork and the updated complete survey of the standing structures on the site has played a fundamental role in this analysis. The results of this research constitute an important advance in the knowledge of this Listed Building and contribute new hitherto unpublished information. The data obtained are the basis for the scientific restoration on this site.
\end{abstract}

Key words: Building techniques; Fortress; Poliorcety; Castilian-Nasrid border; Andalusia; Late Middle Ages; Archaeology.

Recibido: 09-01-2019. Aceptado: 29-03-2019. Publicado online: 04-05-2020

\section{Cómo citar este artículo / Citation}

García-Pulido, L. J., Navarro Palazón, J. y Ortega Camacho, F. 2020: "Análisis de las estructuras emergentes del castillo de La Peña, cabeza de la encomienda calatrava de Martos (Jaén)", Arqueología de la Arquitectura, 17: e092. https://doi.org/10.3989/arq.arqt.2020.001

Copyright: (C) CSIC, 2020. (c) UPV/EHU Press, 2020. Este es un artículo de acceso abierto distribuido bajo los términos de la licencia de uso y distribución Creative Commons Reconocimiento 4.0 Internacional (CC BY 4.0).

luis.garcia@uma.es / ORCID iD: https://orcid.org/0000-0002-2905-0656

julionavarro@eea.csic.es / ORCID iD: https://orcid.org/0000-0003-4698-5506

fernandoortegacamacho@gmail.com / ORCID iD: https:/orcid.org/0000-0001-9542-5885 


\section{INTRODUCCIÓN}

El castillo de La Peña constituyó la cabeza de partido de la encomienda calatrava de Martos (Fig. 1). Dominó el extremo oriental de la campiña sur de Jaén, delimitada al oeste con la de Córdoba, al sur con las sierras del poniente granadino y al norte con el valle del Guadalquivir.

Esta comarca se caracteriza por ser bastante accidentada, con abundantes zonas montañosas, destacando el macizo calcáreo de La Peña, que alcanza 1003 m s. n. m. en su punto más elevado. Este promontorio con forma sensiblemente cónica se alza ejerciendo el control visual sobre una extensa superficie de la campiña jiennense, que queda delimitada por las sierras de la Grana al noreste (1254 m s. n. m.), de la Caracolera al suroeste (1340 m s. n. m.), de la Pandera y de Alta Coloma al sureste (1763 y $1662 \mathrm{~m} \mathrm{s.} \mathrm{n.} \mathrm{m.} \mathrm{respectivamente).}$

En las faldas de La Peña está atestiguada la presencia humana desde el Neolítico, conservándose restos arqueológicos de época íbera ${ }^{4}$, romana ${ }^{5}$, visigoda ${ }^{6}$ y medieval. De este último periodo destacan los restos de sus murallas urbanas y la que es conocida como fortaleza Baja de Martos.

Poco después de la batalla de las Navas de Tolosa en 1212, estas tierras ganadas por la Corona de Castilla fueron donadas a la Orden de Calatrava. Martos se erigió como cabeza de partido de los territorios controlados por esta en el Alto Guadalquivir. Por su emplazamiento y condición de fortaleza natural, La Peña (Fig. 2) fue la sede escogida por la mayoría de los maestres de la orden como símbolo de su poder y referente desde el que se dominaban las tierras de la encomienda de Martos. Su fuerte carácter defensivo desempeñó una función primordial en este territorio de frontera con el reino nazarí de Granada entre los siglos XIII y XV. Tras la conquista de Granada, sus cometidos militares y estratégicos

\footnotetext{
4 En torno al siglo V a.C., ya existía un oppidum en la zona ocupada por el casco histórico del municipio (López 1983: 71 y 81).

5 El emperador Augusto otorgó a Martos el título de Colonia Augusta Gemella Tuccitana. La ciudad creció en las faldas de La Peña, ubicándose en su parte más llana el foro romano. En la meseta situada al oeste se conservan aparejos de mampostería ciclópea, que podría corresponder al periodo republicano (Cano y Serrano 2009: 67-81; Bonilla 2013: 61).

6 En este periodo, Tucci mantuvo una población de cierto estatus, siendo sede episcopal hasta la conquista musulmana y una de las pocas ciudades que acuñó su propia moneda, convirtiéndose en cabeza de la campiña occidental. Se han localizado restos de varias edificaciones visigodas en la zona más llana del municipio (Serrano Peña, J. L y Cano Carrillo, J. C. 2004: Carta Arqueológica Municipal de Martos. Archivo de la Delegación Provincial de Cultura de la Junta de Andalucía de Jaén, Jaén, documento inédito).
}

decayeron, lo que ocasionó su paulatino abandono por su inaccesibilidad.

Su carácter icónico en la comarca marteña (Fig. 3) se ha visto preservado por la dificultad que presenta la subida al recinto, lo que hace que sus restos sean un ejemplo representativo de la arquitectura militar bajomedieval.

El castillo contó con una relevante torre del homenaje (T1), un recinto murado y torreado superior y otro inferior con aljibe y alberca (A), separados ambos por un foso excavado en la roca (Fig. 4). De todos estos elementos aún subsisten suficientes estructuras para poder analizar su disposición original y evolución en el tiempo, así como las técnicas constructivas utilizadas.

$\mathrm{Si}$ en otras fortalezas del entorno se han acometido estudios detallados con motivo de los trabajos de restauración llevados a cabo, del castillo de La Peña tan solo existen breves descripciones que no han llegado a registrar pormenorizadamente sus restos emergentes ni a profundizar en su configuración arquitectónica. El análisis de la información obtenida durante este proceso de documentación ha aportado nuevos datos e hipótesis a las conocidas previamente.

\section{LA IMPORTANCIA TERRITORIAL DE MARTOS Y LA PEÑA}

La islamización de la campiña de Martos pudo haber sido temprana, habiendo atravesado el ejército de Tariq estas tierras al poco de entrar en la Península Ibérica, discurriendo por la vía romana que unía Astigi (Écija) con Cástulo (Chalmeta 2003: 151) durante su expedición a Toledo.

La rebelión de los muladíes a finales del siglo IX supuso que estos también se hiciesen dueños de un pequeño territorio en esta zona y que se levantaran en sus castillos contra la autoridad emiral. El historiador cordobés 'Arīb b. Sa'd, describió en su crónica sobre al-Andalus la sublevación ocurrida en Tušš (Mārtuš) en el año 906 (Burgos 1998: 38). Tras tomar la plaza y obtener juramento de fidelidad, en 912 el propio emir 'Abd al-Rahman III se estableció en la fortaleza marteña, para acabar definitivamente con la revuelta muladí encabezada por 'Umar ibn Ḥafșūn.

Se ha postulado la existencia de un hiș̣n en La Peña ya en esta época, que habría tenido por objeto el control territorial de las campiñas jiennense y cordobesa, posibilitando la conexión visual con otros asentamientos 

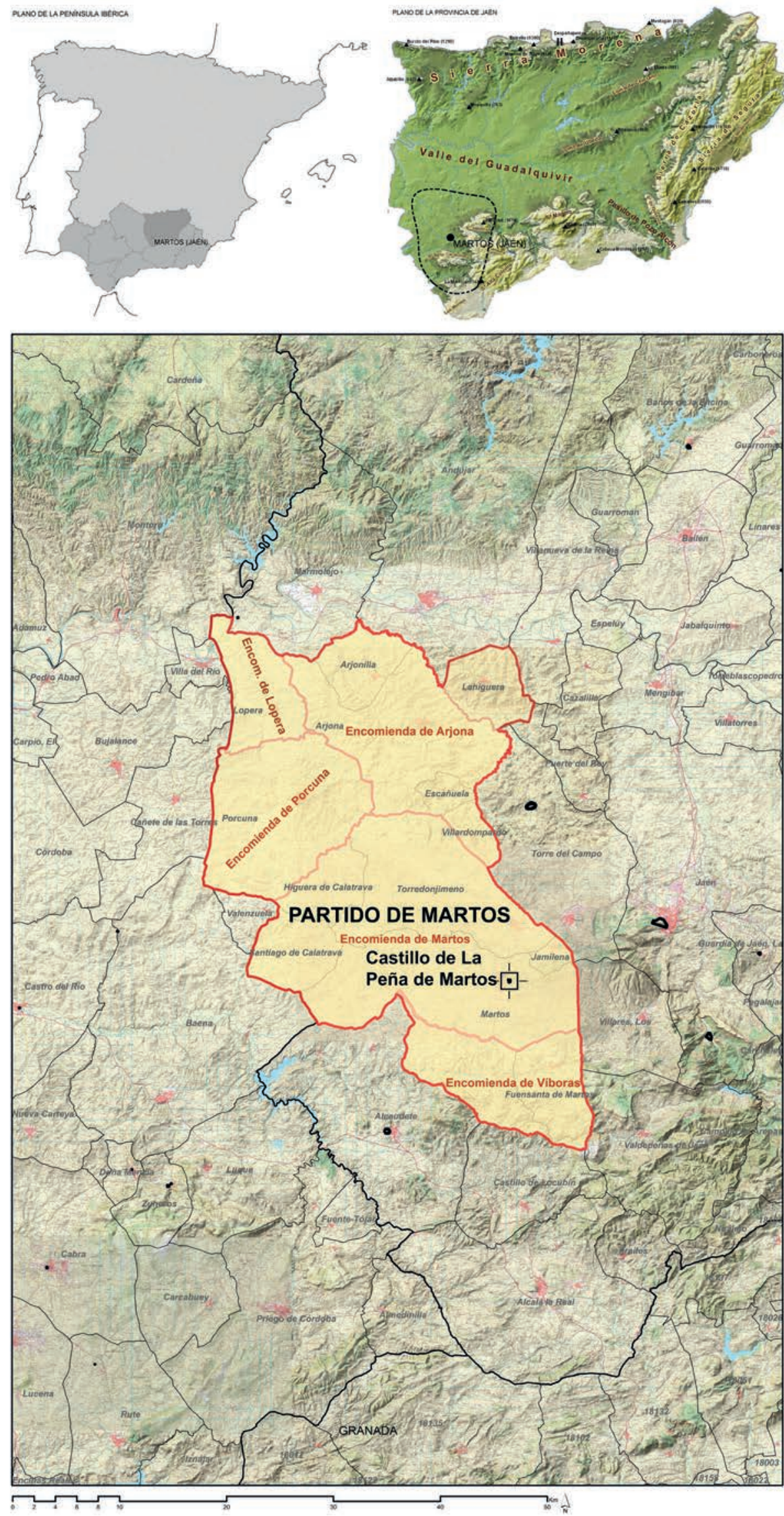

Fig. 1. Localización del castillo de la Peña de Martos en la actual provincia de Jaén, a partir de los límites territoriales señalados en el Mapa geográfico del Partido de Martos perteneciente a la Orden de Calatrava de 1785. Plano de los autores. 


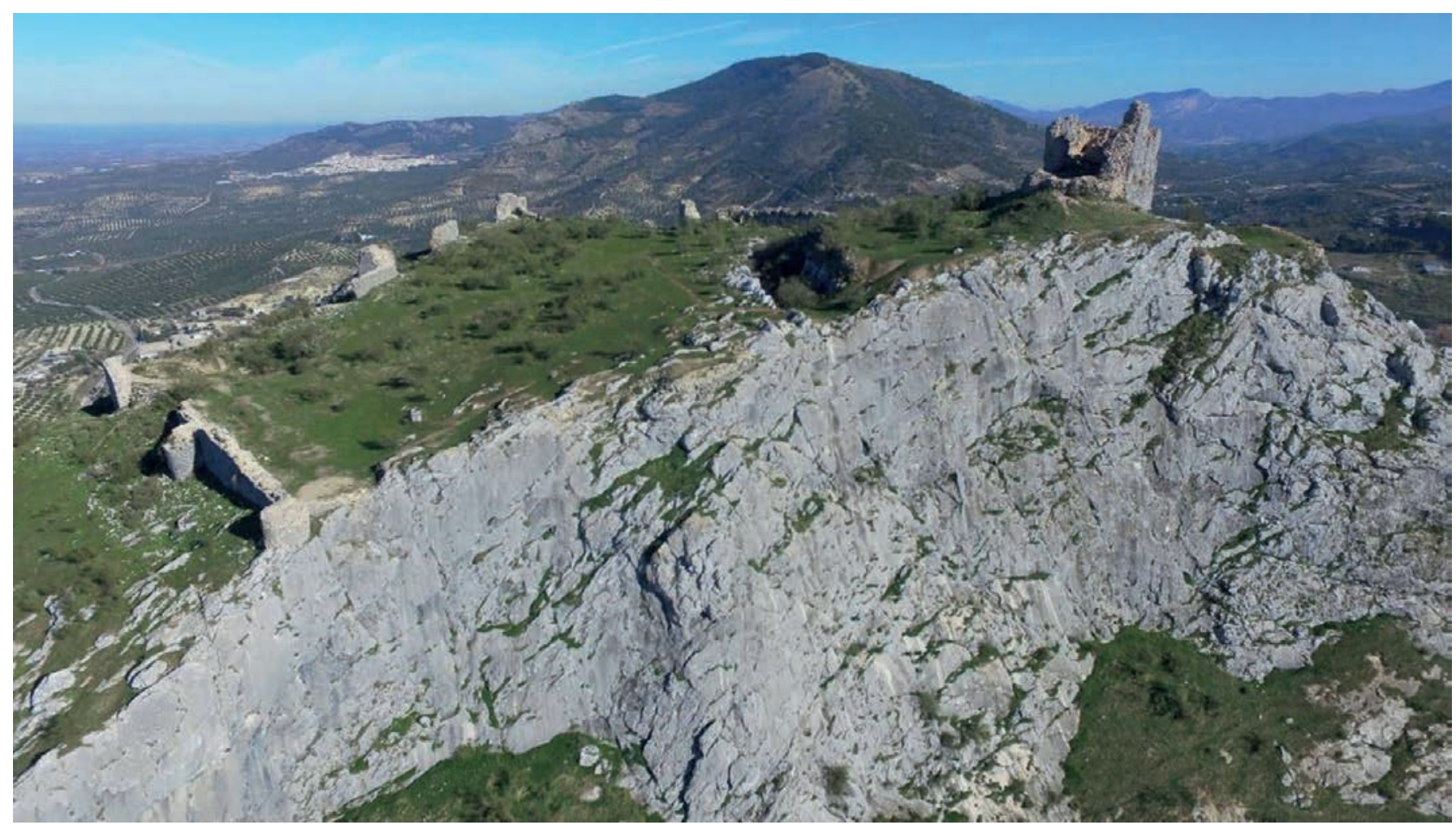

Fig. 2. Vista aérea del Castillo de Martos desde el oeste, con el fondo de la Sierra Sur de Jaén. Fotografía de los autores.

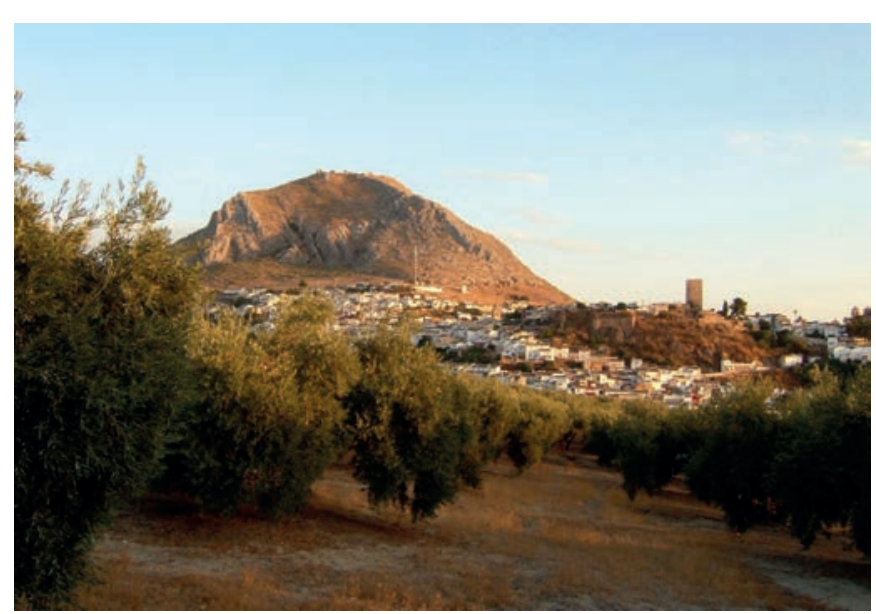

Fig. 3. Vista tomada al norte de Martos. En primer plano se aprecia la silueta de la torre del homenaje y restos del trazado murario de la fortaleza baja. En segundo plano La Peña de Martos, con los restos de la fortaleza en la cima. Fotografía de los autores

fortificados como Arjona, Lopera, Baena, etc. (Gutiérrez 2009a: 25 y 52, 2013).

En el siglo X, la kūra de Ŷāyān (Jaén) contaba con 16 distritos, siendo Tušš la cabeza de uno de ellos, donde confluían la mayor parte de los caminos de la zona. Las fuentes árabes le otorgan el estatus de hiṣn con un fuerte papel militar como principal defensa de Jaén, contando con el control administrativo del territorio circundante (Castillo y Alcázar 2006: 159).
Más tarde, el califa Alī ben Hamudal-Nāșir inició en Martos su reinado, poniendo fin a la guerra civil de comienzos del siglo XI, que concluyó con la fragmentación de al-Andalus en los reinos de taifas. Tušš perteneció desde 1028 a la kūra de Ilbira (Elvira), bajo la dinastía zirí, quedando finalmente del lado de la de Sevilla, bajo el dominio abadí, pues, mediante un pacto entre Ibn 'Ammār y Alfonso VI de Castilla, el primero arrebató en 1085 la plaza de Martos al rey 'Abd Allāh de Granada (Aguirre y Jiménez 1979: 190).

La batalla de las Navas de Tolosa en 1212 supuso el declive del poder almohade en la comarca de Martos. Tras esta contienda, los castellanos definieron una primera marca fronteriza que controlaba los pasos de Sierra Morena, dominando un pequeño territorio y algunas plazas como Vilches, Tolosa y Baños de la Encina (Fig. 5a). Ante esto los andalusíes reaccionaron construyendo y reforzando numerosas fortalezas.

El rey Fernando III empezó la conquista del valle del Guadalquivir aprovechándose de la debilidad y de los enfrentamientos internos de los almohades. Fruto de estas disensiones aparecieron diferentes reinos rebeldes que desafiaron al poder del califa 'Abd Allāh al-'Ādil, destacando la figura de 'Abd al-Mu'minal-Bayyāsī, quien estaba enfrentado a su hermano el gobernador de Sevilla y controlaba la ciudad de Baeza, junto a gran 


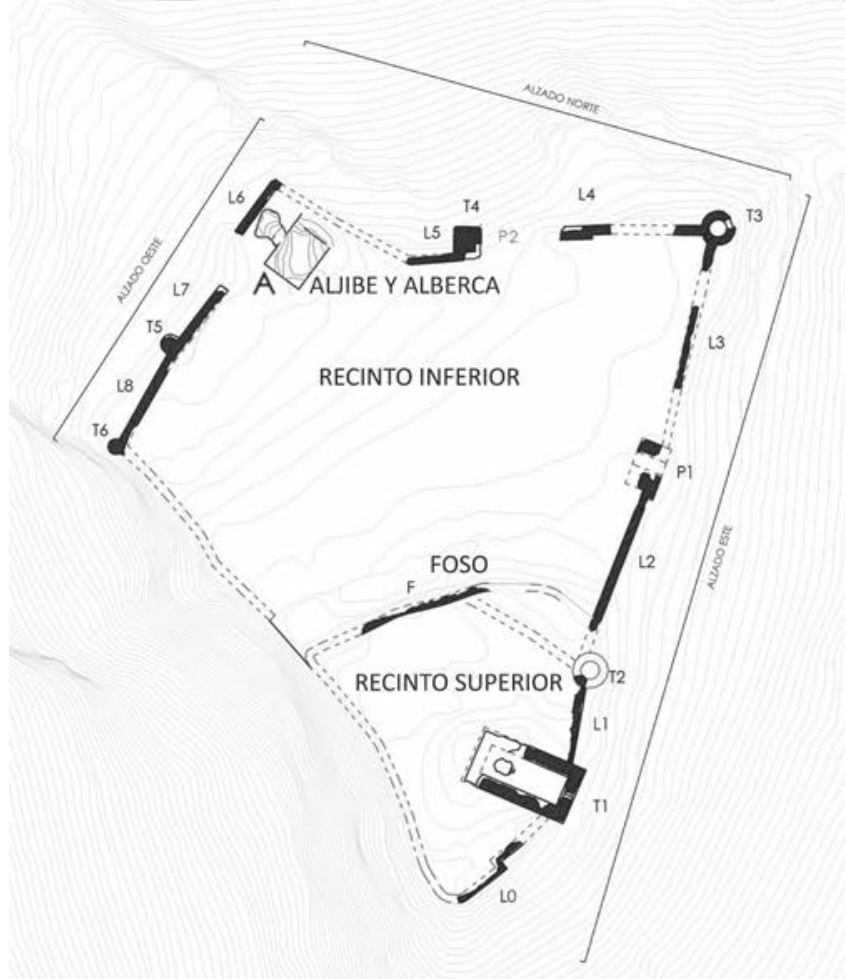

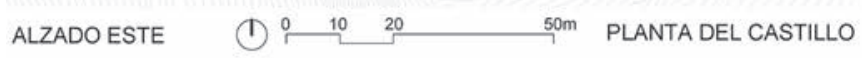

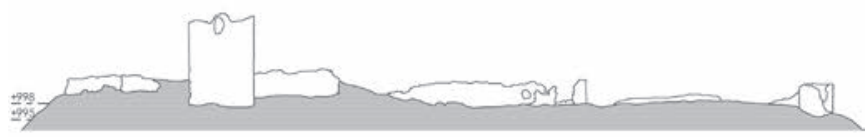

ALZADO NORTE

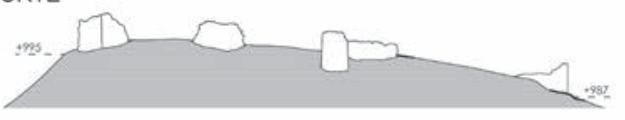

ALZADO OESTE

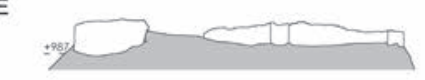

SECCIONN EJE ESTE-OESTE

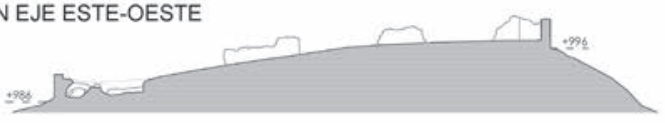

SECCIÓN EJE NORTE-SUR

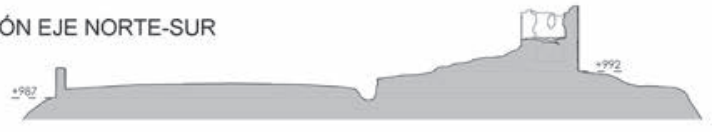

Fig. 4. Esquema con la planta, alzado y secciones generales del Castillo de La Peña. Plano de los autores.

parte del territorio de la actual provincia de Jaén. En 1224, Fernando III comenzó sus primeras incursiones en los territorios del Alto Guadalquivir apoyando a alBayyāsī (González 1980), empezando así una serie de campañas en las que atacó distintos castillos. Un año más tarde pusieron cerco a Jaén, y, tras la toma de la

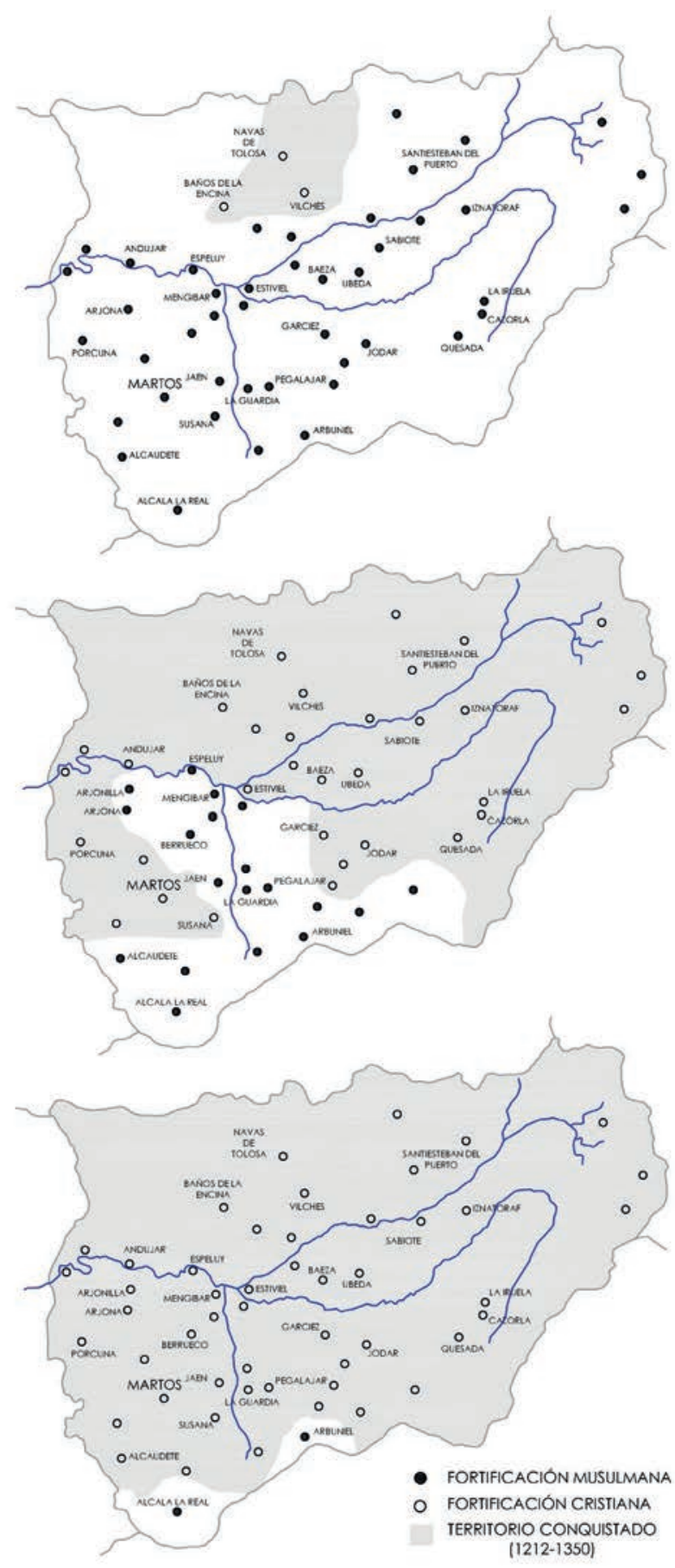

Fig. 5. Esquema con el mapa fronterizo del Alto Guadalquivir (sobre los límites de la actual provincia de Jaén) entre 1212-1224 (5a, arriba), en torno a 1242 (5b, centro) y hacia 1350 (5c, abajo). Dibujo de los autores a partir de Castillo y Alcázar 2006: 171 y 173.

ciudad, este último consiguió el cargo de gobernador, por lo que quiso declararse independiente del poder almohade con la ayuda militar del monarca castellano, convirtiéndose en su vasallo en el pacto de 1225 de las Navas de Tolosa. Por este tratado, Fernando III recibió la población de Martos, además de otras como Andújar, 
Baños de la Encina, Salvatierra, Capilla y el Alcázar de Baeza, modificándose la línea fronteriza que se expandía por el margen izquierdo del Guadalquivir.

Este territorio se encontraba muy fortificado $(\mathrm{Gu}-$ tiérrez 2009b: 48), contando con castillos de entidad y otros menores consistentes en pequeños recintos ubicados en puntos estratégicos, tales como Torre Ben-Zalá o Torre Alcázar (Fig. 6), que funcionarían como albacaras defensivas para proteger a la población campesina y almenaras para controlar las vías de comunicación.

Tras la muerte de al-Bayyāsī en 1226 durante un ataque a Sevilla, se produjo una sublevación mudéjar, a la par que estos emigraron masivamente hacia tierras andalusíes, lo que obligó a los castellanos a llevar a cabo un repoblamiento ante el peligro de perder los territorios conquistados.

Las tensiones que se dieron en Martos fueron contenidas por el conde Álvaro o Alvar Pérez de Castro, a quién Fernando III le confió la tenencia de La Peña (Cressier y Salvatierra 2014: 465-470) y de la ciudad, como un punto estratégico clave en este territorio fronterizo, configurándose como ciudad avanzada del poder castellano en estas tierras. Esta situación hizo que los musulmanes de Arjona la tratasen de reconquistar. Así habría sucedido en un asedio ocurrido en 1227, recogido con carácter legendario en numerosas crónicas medievales desde el reinado de Alfonso X (Gutiérrez 2011). Este episodio bélico no fue protagonizado por el primer rey nazarí de Granada, según relató en 1595 Diego Pérez de Mesa en su libro Grandezas de España (Olivares 1992: 180), sino por Abū-1-'Ulā, hermano del califa almohade Abū Muḥammad' Abd Allāh al- 'Ādil, quien aprovechó la desprotección de Martos durante un viaje a Toledo de Álvaro Pérez de Castro y la expedición de su sobrino Tello Alfonso de Meneses a la campiña cordobesa, que estaba al cargo de la defensa de la ciudad. Este último tuvo noticia del asedio cuando se encontraba en Víboras (Fig. 7), a escasos $15 \mathrm{~km}$, regresando de inmediato a Martos. Aunque consiguieron defender la fortaleza de la villa, no pudieron hacer lo mismo con la de La Peña, que fue tomada por el ejército de Abū-1-'Ulā (González 1980). Estos hechos provocaron que Fernando III regresara a estas tierras, ante lo cual, los andalusíes se retiraron a Arjona.

Tras estos acontecimientos, a finales de 1228 se encomendó a la Orden de Calatrava la defensa, administración y estructuración del territorio correspondiente a Martos y sus términos (Gutiérrez 2009b: 34), incluyéndose también las poblaciones y territorios de Víboras y Porcuna (Fig. 8). La encomienda encabezada por la Peña de Martos acabó por englobar a Torredonjimeno, Jamilena, Santiago e Higuera de Calatrava y otros núcleos de menor entidad como Benzalá, Torre Fuencubierta, Torre García o Monte Lope Álvarez?

En 1238 el primer monarca nazarí, Muhammad ibn al-Ahmar, puso cerco a la fortaleza, posiblemente como reacción a las ofensivas que se estaban realizando contra la ciudad de Jaén. Años más tarde, en 1245 tuvo lugar una nueva incursión en el territorio marteño por parte de contingentes gazules procedentes del reino de Granada, poniendo sitio a la ciudad, intentando frenar la presión y los asedios cristianos en tierras granadinas. El cerco fue levantando de nuevo al llegar los refuerzos enviados por Fernando III (Menéndez 1977: 744).

Martos fue la base de operaciones para la conquista de Jaén, culminada en el año 1246 (Ansón 1998: 130131). A partir de este momento la frontera con el reino nazarí de Granada quedó localizada al sur de esta encomienda (Fig. 5b).

Además, el final del siglo XIII coincidió con un periodo de gran agitación en el seno de la Orden de Calatrava (Ruiz 2010: 64; Gómez de Terreros 2010) que dio lugar a una etapa de inestabilidad política en el que se sucedieron distintos maestrazgos.

Tras el fallecimiento de Fernando IV en Jaén en 1312, se produjo de nuevo una etapa de inestabilidad que fue aprovechada por Ismaîl I para realizar uno de los más intensos ataques sobre la comarca marteña en 1325, tras el desconcierto castellano producido por la derrota en una expedición contra Granada. El monarca nazarí llegó a la villa de Martos, a la que sometió a un duro cerco donde el ejército granadino habría utilizado la pólvora, siendo la primera aparición atestiguada de esta nueva arma en tierras jiennenses (Eslava 1990: 155156). La ciudad fue tomada, saqueada y asolada por los granadinos, tal y como narró Ibn al-Jațīb (Burgos 1998). No se consiguió por el contrario tomar el castillo de La Peña, que contuvo el ataque con un reducido número de defensores que organizaron la contraofensiva que liberó a Martos del asedio.

A lo largo del siglo XIV, el empuje castellano fue desplazando la frontera del reino de Granada hacia el sur de Martos (Fig. 5c) (García 1987: 84), lo que no evitó que en el siglo XV continuaran las expediciones

7 Existen discrepancias para definir los límites con las encomiendas vecinas de Víboras y Porcuna, puesto que no estaban claras ni tan siquiera para la propia Orden de Calatrava. A finales del siglo XVIII, estas últimas estaban ya englobadas en la de Martos (Ruiz 2010: 154). 

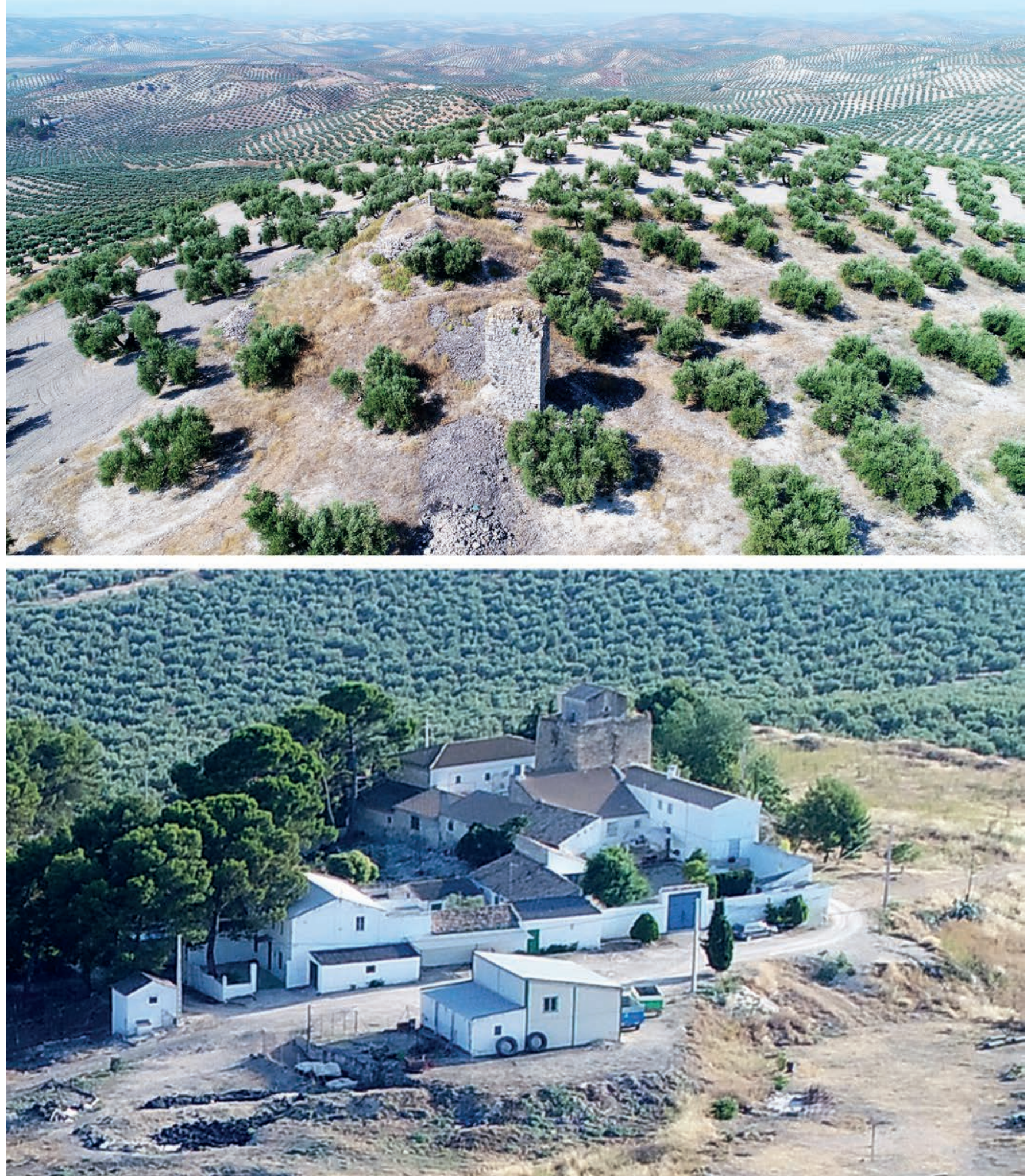

Fig. 6. Imágenes aéreas del estado actual de los yacimientos de Torre Ben-Zalá (arriba) y Torre Alcázar (abajo). Fotografía de los autores. 

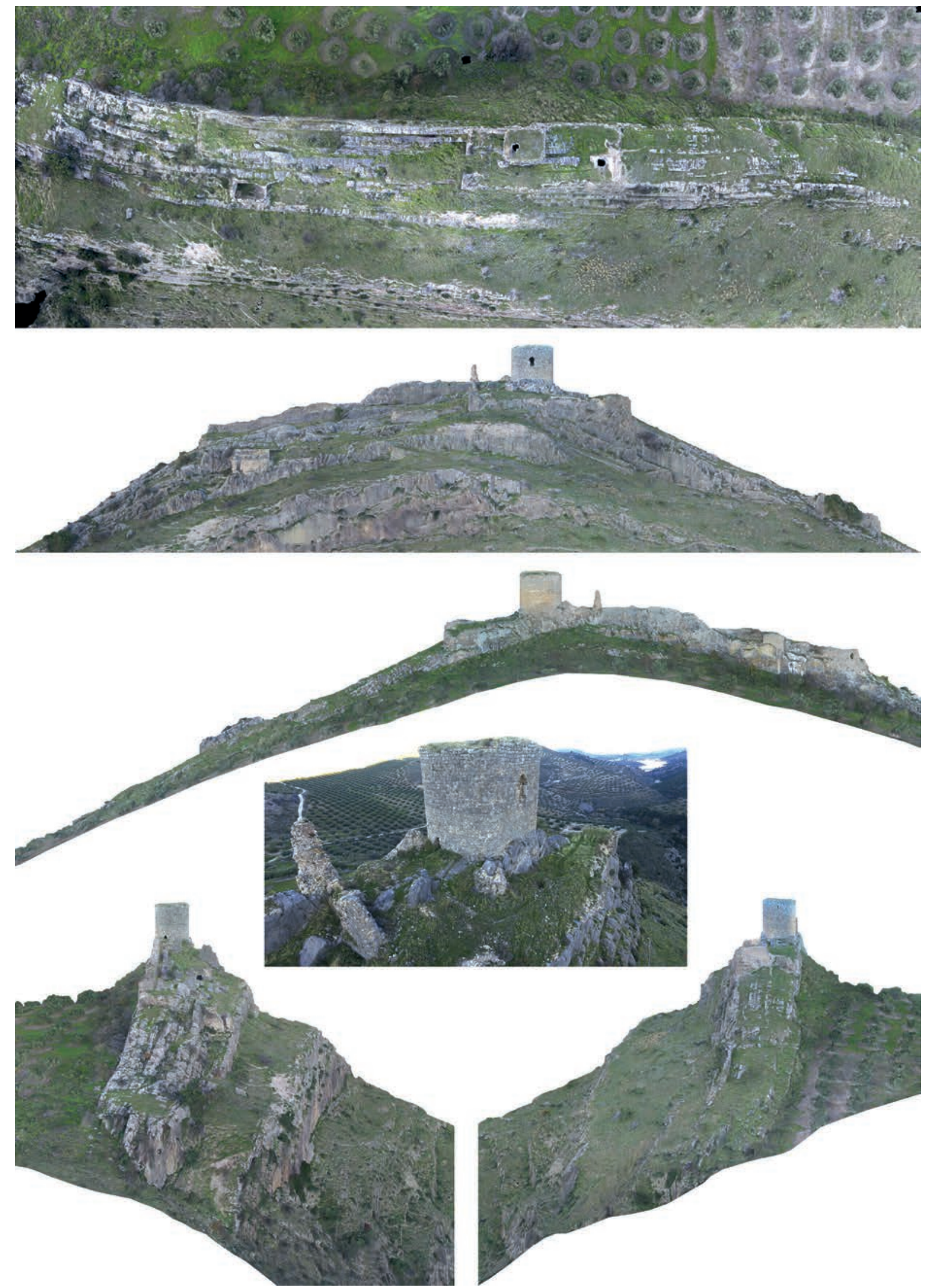

Fig. 7. Planta y alzados fotogramétricos del castillo de Víboras, situado al sur del término municipal de Martos, en el que destaca su torre del homenaje. Fotografías y ortofotografías de los autores. 


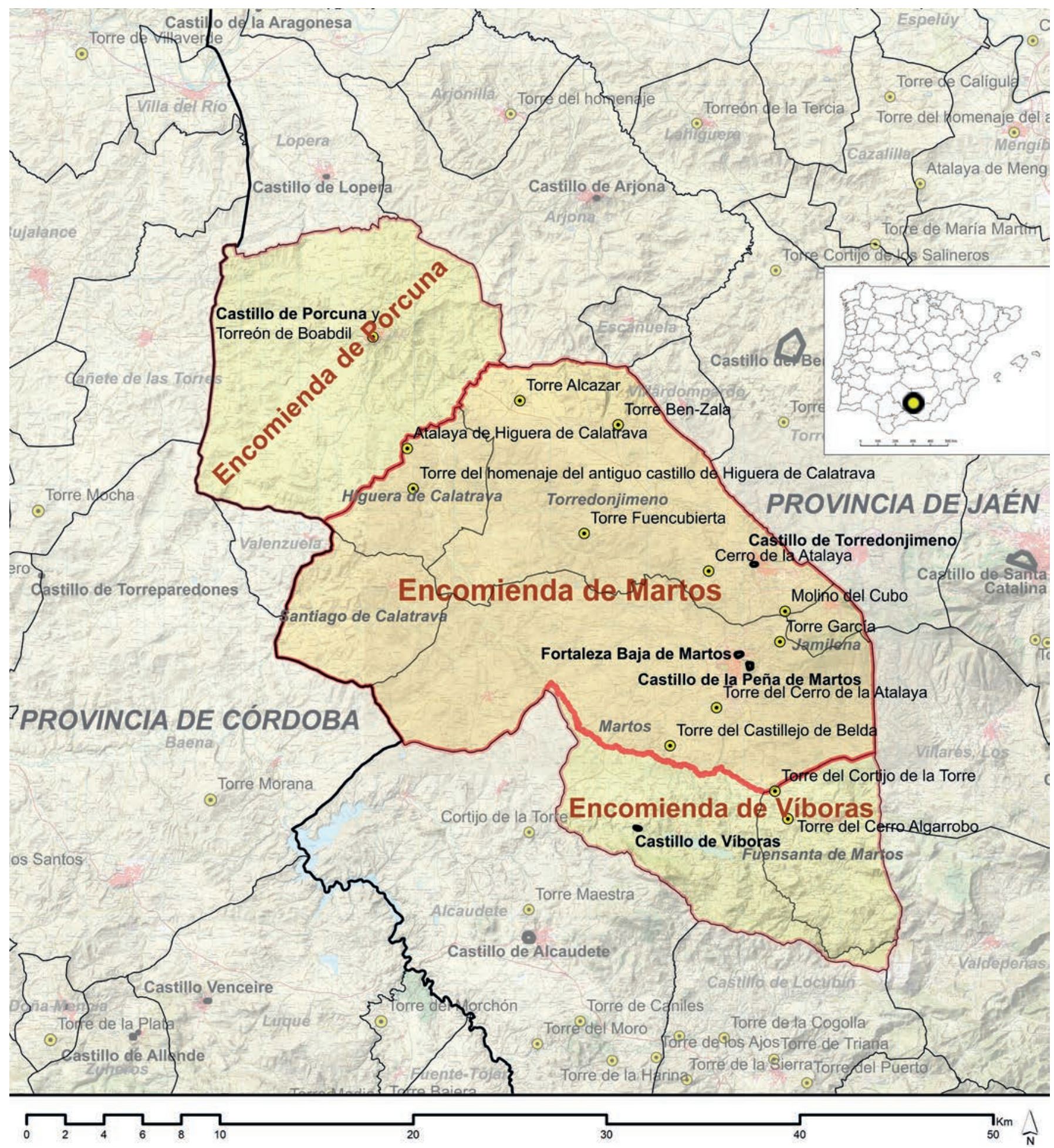

Fig. 8. Extensión de las encomiendas de Martos, Víboras y Porcuna durante la baja Edad Media y principales estructuras defensivas en su territorio. Plano de los autores.

nazaríes contra la ciudad, destacando la que tuvo lugar en la segunda mitad de la centuria, ordenada por Abū al-Hasan, el Muley Hacén de las crónicas castellanas (Capel 1994).
Como consecuencia de todos estos ataques y de la situación de frontera con el reino de Granada, la encomienda de Martos realizaría refuerzos y ampliaciones en sus defensas de forma constante, llevando a cabo 
intervenciones con objeto de configurar una sólida protección a la población. En la fortaleza urbana se siguió manteniendo el esquema de ciudad andalusí con un doble recinto amurallado, uno para albergar en su interior la alcazaba y otro externo que protegía a la medina (QuesadaGarcía y Fernández 1991). Las construcciones previas, realizadas en tapial, fueron revestidas de mampostería, quedando la muralla con una serie de torres macizas de planta circular, cuadrada y rectangular. Esta forma de refortificar había sido practicada sistemáticamente en el Campo de Calatrava, donde esta orden militar había obtenido sus primeras encomiendas unas décadas atrás (Aranda et al. 2016). Además, la creciente generalización del uso de la artillería pirobalística propició que en muchas fortalezas se realizaran paulatinas reformas para adaptar sus elementos arquitectónicos defensivos y ofensivos a las nuevas necesidades, tales como el engrosamiento de algunos paramentos de las murallas y torres, así como el suavizado de las aristas, que a partir de ahora se ejecutarían preferentemente con forma redondeada, tal y como puede observarse en algunas estructuras del castillo de La Peña o en la torre del homenaje del castillo de Víboras (Fig. 7).

También se levantaron fortalezas de nueva planta como la de Higuera de Calatrava, Torredonjimeno o Jamilena (Gutiérrez 2009b: 50), encargadas del control y de la vigilancia de los principales caminos que unían Martos con Jaén y Porcuna. Además, estos recintos sirvieron para crear un escudo que permitiera la colonización de estas posiciones calatravas. Todos estos castillos contaron con un recinto amurallado que servía tanto de residencia de la guarnición militar como de refugio para la población, dentro del cual se alzaba la torre del homenaje. De la misma manera se reforzaban las diferentes torres vigías existentes o construidas por la orden en puntos estratégicos y/o vinculados a las comunicaciones (Fig. 8).

Aparte de servir como centro fiscal y jurisdiccional, tenían un importante papel defensivo, de organización territorial y de representación del poder. En algunas fortalezas preexistentes se tuvo que modificar su organización y estructura para acoger diversas dependencias residenciales y conventuales - salas capitulares, refectorios, capillas, claustros - así como espacios de almacenaje tales como graneros o bodegas (Molina y Eiroa 2009: 183). La presencia de grandes torres del homenaje también destacó como imagen del poder feudal calatravo, además de servir de reducto defensivo, y acabó influyendo en la arquitectura militar andalusí.

En el año 1489 la administración de las órdenes militares fue asumida por el rey Fernando el Católico y tres años más tarde era conquistada la capital del reino nazarí, desapareciendo definitivamente la inestabilidad fronteriza. La documentación conservada muestra el imparable deterioro del castillo de La Peña a lo largo del siglo XV, que ya había comenzado en la centuria anterior. En el año 1459 se mandó reconstruir la iglesia de Santa Catalina, situada dentro del recinto (Ruiz 2010: 40). En 1491 se tuvo que trabajar en la puerta principal, en parte de sus murallas, en el lagar y de nuevo en su iglesia. Dos años después se volvían a ordenar las mismas reparaciones y algunas más centradas en la torre mayor, las casas del horno y el molino, que estaban para caerse. La inaccesibilidad que presentaba esta fortificación, tan necesaria en momentos de conflicto, hizo difícil su sostenimiento en tiempos de estabilidad prolongada. Por ello, el comendador de la Orden de Calatrava decidió trasladar su morada a la fortaleza urbana, aun cuando esta también se estaba deteriorando, dando cuenta los visitadores de las reparaciones necesarias en 1505 y 1514 (Recio y López 2002).

En una revista a la fortaleza de La Peña realizada en 1557 se realizó un inventario de las armas y determinados bienes muebles existentes en ella, la mayoría de ellos inservibles, indicando además que el alcaide frey Gutierre López de Padilla ya no se encontraba en ella (López 2003). Con esta relación se ponía de manifiesto que muchos de los utensilios militares estaban en mal estado o eran ya obsoletos, meras reliquias bélicas del pasado.

Durante la guerra de la Independencia, se produjeron enfrentamientos a las afueras de Martos, llegando los invasores a ocupar el castillo de La Peña en 1808 (Cano y Serrano 2009: 70). Con todo, esta implantación debió ser solamente un posicionamiento estratégico en un emplazamiento dominante, puesto que no hay evidencias de construcciones de este periodo en superficie.

\section{HISTORIOGRAFÍA DEL CASTILLO DE LA PEÑA}

Entre las primeras referencias históricas generales, destaca la que realizara en 1579 Diego de Villalta, vecino de Martos y uno de los últimos ocupantes de la fortaleza. Aún en esos postreros momentos la referiría como "inexpugnable" y que estaba "cercada de fuertes y altas murallas y torres y cubos muy espesos, puestos en la cerca y cuadra [...] Tiene dentro de lo cercado una torre del homenaje grande y muy hermosa, con un foso muy hondo, todo cavado al derredor y cortado en la peña viva, con su puente levadizo de madera asida con fuertes y recias cadenas" (Villalta 1982 
[1579]). En su obra Historia de la Antigüedad y fundación de la Peña de Martos recogió dos grabados de factura diferente, en los que se representaron los edificios principales de Martos en una vista desde el norte, con el fondo omnipresente de este monte (Fig. 9). El segundo de ellos incluyó un camino que conecta la fortaleza Alta con la Baja y con la ciudad, por el que discurre la figura del dios Marte.
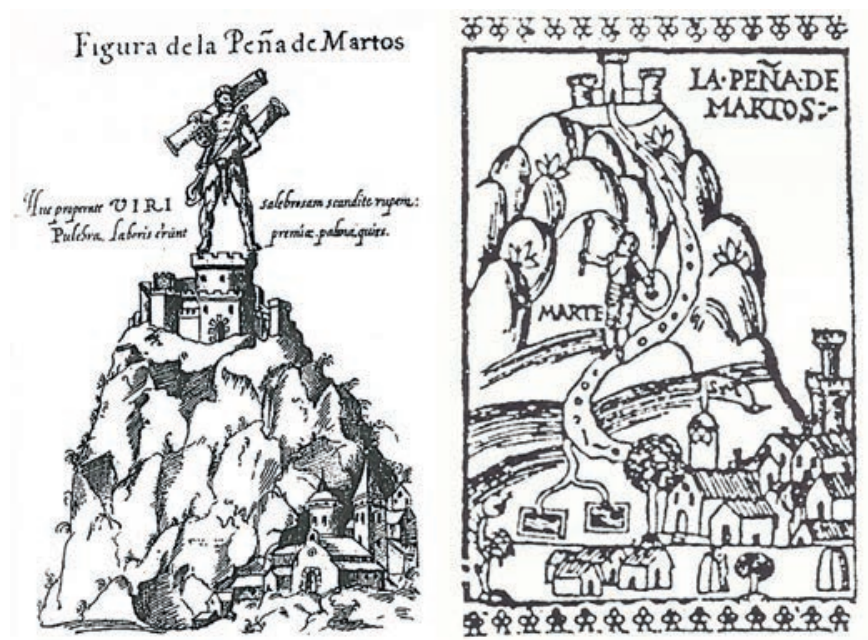

Fig. 9. A la izquierda, imagen de la portada de la obra de Diego de Villalta. Los textos que la acompañan ponen de manifiesto la dificultad del camino de ascenso al castillo, representando en la cima a Hércules con sus columnas. A la derecha, ilustración en el interior de la misma obra con el camino entre La Peña y Martos, por el que desciende el dios de la guerra.

En estas ilustraciones, el recinto más elevado muestra un primer frente amurallado al norte, con torreones en los extremos y una torre-puerta fortificada con carácter monumental en su punto central. En la primera imagen, que presenta más detalle y fue utilizada para la portada de su libro, se aprecian murallas posteriores de las que emergen torres, pudiendo destacar un torreón de dimensiones superiores a los demás, que vendría a corresponder con la torre del homenaje.

En 1639, Ximena Jurado también representó el castillo de La Peña en su obra Antigüedades del reino de Jaén. La dibujó con una torre-puerta orientada hacia villa de Martos con su recinto amurallado, en el que se integraría el de la fortaleza Baja (Recio et al. 2002: 70) (Fig. 10).

En 1791, Antonio Ponz Piquer indicaría que "en la cumbre permanece un fuerte castillo abandonado en su ruina como los demás de España" (Ponz 1791: 268), tal y como puede apreciarse en un grabado anónimo de Martos y de La Peña de esa centuria ${ }^{8}$ (Fig. 11). A mediados del siglo XIX, Pascual Madoz (1848: Tomo XI, 266)

8 http://www.juntadeandalucia.es/institutodeestadisticaycartografia/fototeca [fecha de consulta: 15/08/2018]

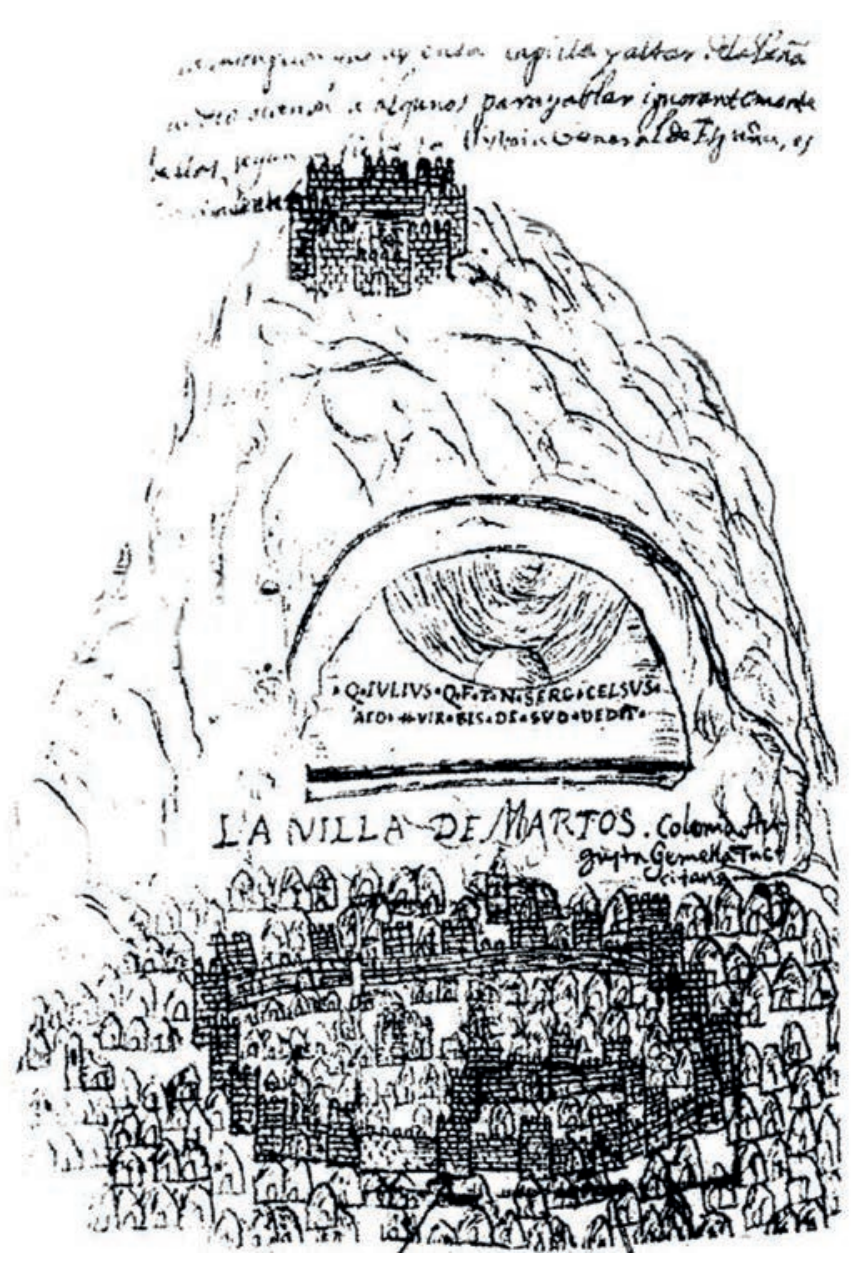

Fig. 10. Dibujo de Ximena Jurado, incluido en su obra "Antigüedades del reino de Jaén" del año 1639, donde se ven La Peña y el recinto amurallado de la villa de Martos.

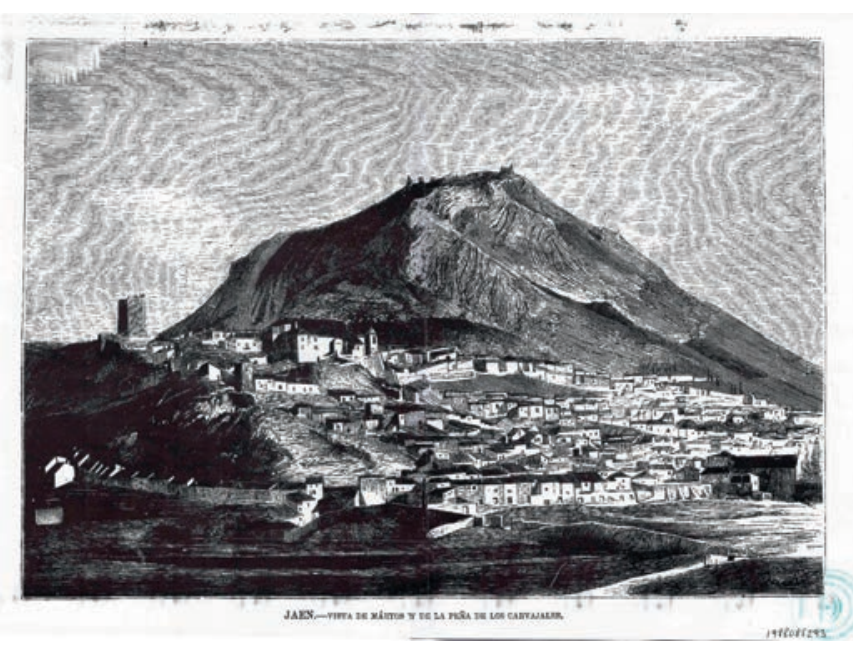

Fig. 11. Grabado de la vista desde el oeste de Martos y La Peña en el siglo XVIII, de autor desconocido.

se referiría al castillo de La Peña como una fortificación que, a pesar del transcurso del tiempo, aún conservaba una solidez asombrosa. 
El primer acercamiento científico a sus vestigios lo realizó Juan Eslava Galán (1990), quien indicó que el castillo de La Peña fue construido por la Orden de Calatrava hacia 1240, aunque en otra parte de su trabajo también fijaría su fundación un siglo más tarde. Postuló la existencia de estructuras de un primitivo castillo andalusí en el "bastión" rectangular que se conserva en el lienzo de la muralla septentrional. Poco después, Francisco Cerezo Moreno dibujaría los restos del interior del aljibe, de la torre circular situada en la esquina nordeste y de la torre del homenaje (Cerezo y Eslava 1989) (Fig. 12).

En 1998, Rodrigo Valdecantos Dema adelantaría la construcción del castillo de la Peña al siglo IX, indicando que habría sido refortificado por la Orden de Calatrava a partir del siglo XIII, construyéndose la torre del homenaje en el siglo XIV. También en 1998, Antonio Burgos Núñez describió las principales fortificaciones del entorno, incluida la de La Peña (Burgos 1998).

El trabajo más reciente fue llevado a cabo por la Asociación para el Desarrollo de la Sierra Sur de Jaén (ADSUR) $)^{9}$, con una somera descripción de los restos emergentes incluyendo un esquema de los alzados, dos secciones y un detalle del aljibe, aunque sin ahondar en sus aspectos constructivos.

Sí se ha abordado con mayor profusión el contexto territorial, destacando las publicaciones del Grupo

9 http://www.adsur.es/contenidos/baul/turismo/turismo_castillos_martos pena_plano.php [Fecha de consulta: 15/08/2018] de Investigación del Patrimonio Arqueológico de la Universidad de Jaén, destacando los estudios de Juan Carlos Castillo Armenteros sobre el señorío calatravo en estas tierras (Castillo y Castillo 2003; Castillo et al. 2013). Estas investigaciones han permitido conocer las transformaciones introducidas por esta orden en las construcciones previas, a partir de la prospección y excavación de varias de las fortificaciones construidas en el Alto Guadalquivir, tales como Alcaudete, Lopera, Sabiote, Villardompardo o Torredonjimeno. Por otra parte, Francisco Ruiz Fúnez ha realizado una descripción de las que se encontraban en este entorno, abordando el contexto social y el papel determinante de estas para la organización y articulación del territorio (Ruiz, 2010).

\section{4. el CAStillo Medieval de LA peÑa DE MARTOS}

Tras la entrega de Martos a la Orden de Calatrava en 1228 , se diseñó una fortaleza que ocupó toda la meseta de la cumbre, aprovechando la orografía del terreno como defensa natural, quedando las hipotéticas estructuras previas amortizadas o absorbidas por completo por las nuevas construcciones. El perímetro murario acabaría definiendo una planta trapezoidal, abarcando una superficie total en torno a los $8550 \mathrm{~m}^{2}$ (Fig. 4).

En la actualidad, la subida a La Peña se realiza por su ladera meridional, por ser la más accesible. Este sendero,
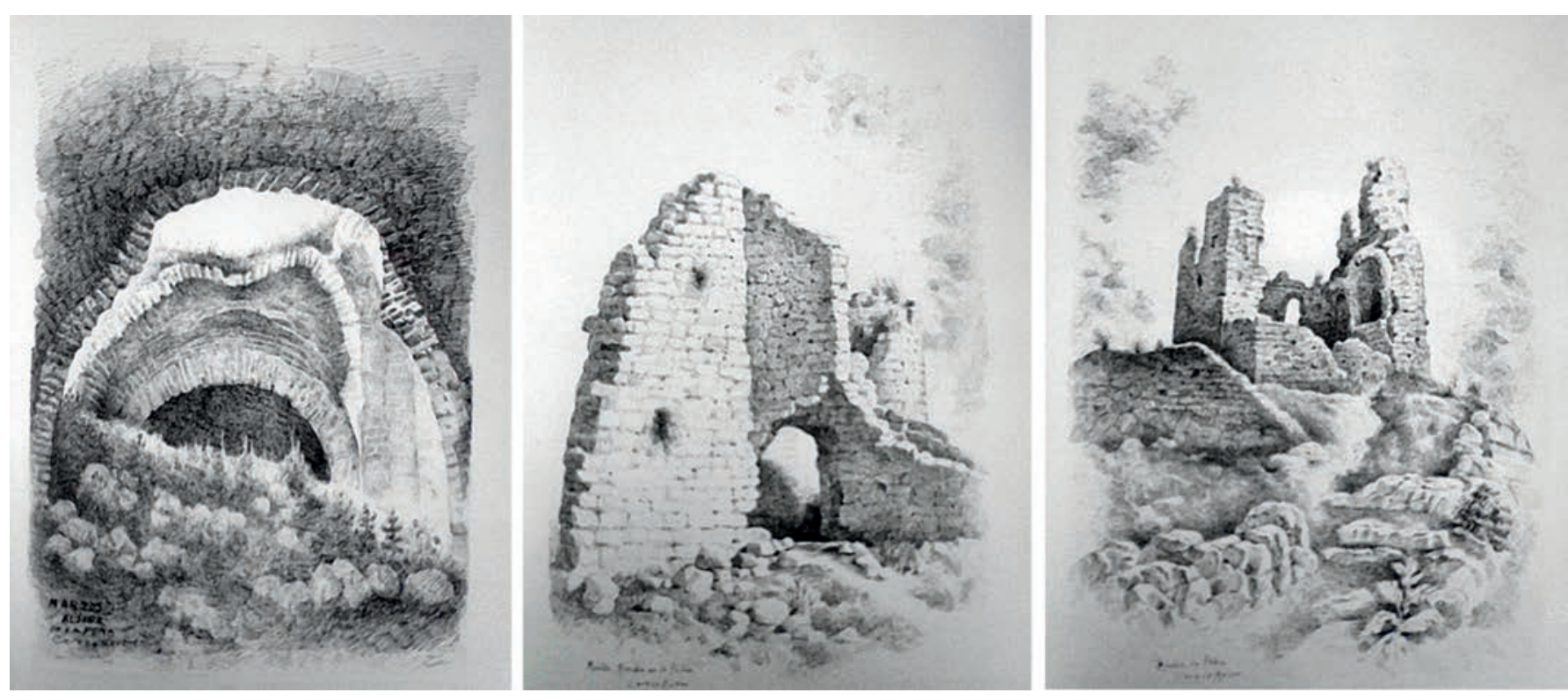

Fig. 12. Dibujos de Francisco Cerezo Moreno publicados en 1989. Izquierda: interior del aljibe del recinto inferior del castillo de La Peña. Centro: exterior de la torre circular del extremo noreste. Derecha: en primer plano se dibujó el foso de la fortaleza y, tras él, los restos de la torre del homenaje. 
ejecutado en 2004, tiene un trazado zigzagueante, con un desnivel de más de $150 \mathrm{~m}$ de altura y una longitud de 480 $\mathrm{m}$ (Fig. 13). La prospección arqueológica realizada entonces dejó constancia de un antiguo camino por este sector, que habría concluido aproximadamente en la parte central del frente murario oriental, en una de las posibles puertas de acceso al recinto fortificado. El trazado medieval que documentó el estudio arqueológico, estaba acondicionado mediante rellenos y estructuras de contención, para así garantizar la estabilidad del camino (Luna et al. 2004: 2010).

Las fortalezas Alta y Baja habrían estado enlazadas por dos lienzos murarios, tal y como relató Diego de Villalta en el siglo $\mathrm{XVI}^{10}$, de la que hoy en día apenas si quedan restos superficiales.

El recinto está dividido por un gran foso excavado en la roca $(\mathrm{F})$ que cuenta con un muro en su lado más meridional, atravesando de este a oeste la planicie de la cima de La Peña, lo que establece una estructura jerárquica en la constitución del castillo, aislando la parte superior del resto del recinto fortificado por medio de un puente levadizo.

$\mathrm{Su}$ anchura llega a ser de más de $6 \mathrm{~m}$ y fue excavado en dirección este-oeste hasta el "mal vecino", como se conoce localmente al precipicio existente en la falda occidental de La Peña. Además, habría actuado como cantera para la obtención del material pétreo utilizado en los muros de la fortaleza.

El foso habría funcionado en seco y se encontraba recorrido por una muralla que delimitaba el reducto superior. Ambos elementos fueron mantenidos una vez se construyó el recinto inferior, separando de manera nítida ambos perímetros.

Además, en su zona este se aprecia un quiebro en el trazado para duplicar la línea de muralla. Este hecho permite plantear la hipótesis de que en esta zona podría encontrarse el puente levadizo o algún otro elemento de control para la conexión entre ambos recintos, que se vería reforzada por la presencia de la torre T2. La existencia de este elemento en el extremo oriental del foso sugiere la presencia de otra en el extremo opuesto, donde se ven indicios de la presencia de una posible torre circular. Esta hipotética torre reforzaría el eje este-oeste del foso, enmarcando el recinto superior entre estos dos elementos circulares.

10 "En la última parte septentrional que mira al norte, hace esta Peña dos puntas que descienden hasta el medio de la misma Peña, y son a manera de hombros que sustentan y tienen la fortaleza que en lo alto está edificada [...]. Salen desde el pie de lo áspero de la Peña dos pedazos de muralla no del todo continuada, que cada uno por su parte desciende y va a dar al castillo bajo, dentro de la cuadra, de los cuales se incluye toda la mayor parte de lo poblado" (Villalta 1982 [1579]).
En el recinto elevado destacan los restos de la torre del homenaje (T1), elemento icónico que es reconocible desde la lejanía del territorio y donde debió de ubicarse la residencia del comendador de la Orden de Calatrava.

En el recinto inferior son visibles los vestigios de un aljibe y una alberca (A). Aparte de los lienzos de la muralla, actualmente no emerge ninguna otra estructura edilicia. Con todo, debió de ser el lugar donde se ubicaron la mayor parte de las construcciones intramuros, entre las que podrían encontrarse la iglesia de Santa Catalina, los hornos, el lagar o los talleres mencionados en las visitas de la orden.

El perímetro murario era continuo en todo el recinto, y en el "mal vecino" existió al menos un parapeto de protección de poco espesor, como evidencian los restos conservados. La muralla fue completada con la construcción de torreones y bastiones reforzando puntos estratégicos. $\mathrm{Su}$ reducido número ${ }^{11}$ es suplido por quiebros y redientes en los muros. Las torres circulares habrían sido huecas, mientras que el resto son macizas, estando algunas de estas adosadas a las murallas a modo de contrafuertes, sin trabazón al menos en la línea de contacto exterior.

\section{ANÁLISIS DE LOS RESTOS CONSERVADOS}

\subsection{Torre del homenaje (T1)}

Los visitadores de la Orden de Calatrava ya advertían en el siglo XVI de la falta de mantenimiento en la torre mayor de esta fortaleza. Aun así, sigue siendo el elemento más presente en todo el conjunto, estando ubicada en la parte más elevada de la meseta (Fig. 14). Tiene planta rectangular, con unas dimensiones de $11 \times 21 \mathrm{~m}$ y se conservan restos de todos los alzados, aunque el oeste y parte del norte se encuentran derruidos desde el suelo del primer nivel que aflora en el terreno.

Fue construida con mampostería bien ripiada, dispuesta en hiladas y con las esquinas trabadas con sillares diferentes, con alturas que oscilan entre los 10 y los 22 $\mathrm{cm}$. Muchos de los que están tallados en piedra arenisca son de acarreo, presentando símbolos, entalles y recortes debidos a un uso anterior en otras edificaciones. La sillería no está en el resto de las torres y cubos del

11 La distancia de estos elementos oscila entre los 20 y los más de $40 \mathrm{~m}$, cifra elevada si la comparamos con las separaciones existentes en otras fortalezas del entorno. 


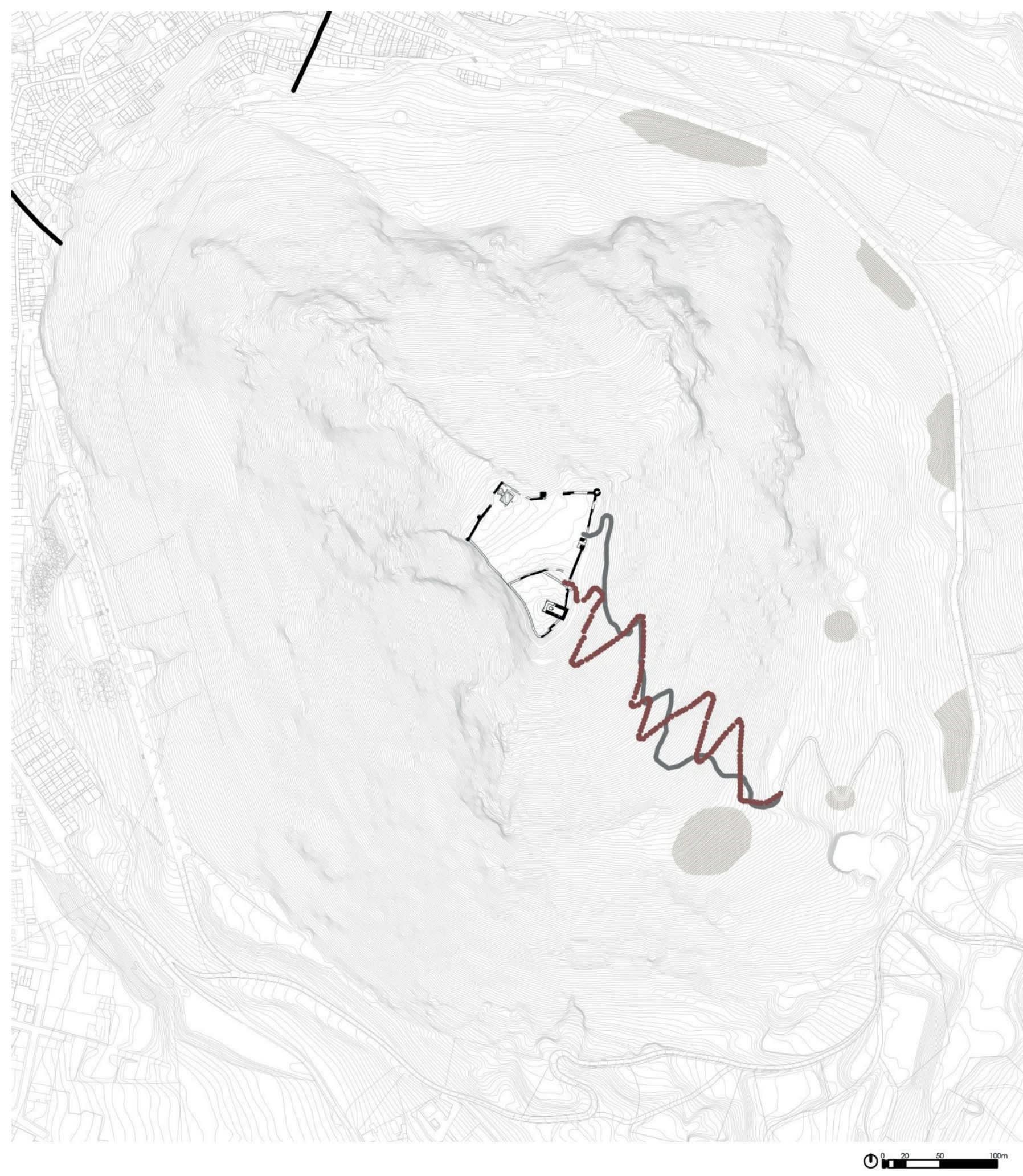

Fig. 13. Camino de acceso al castillo de La Peña. El trazado gris representa el camino ejecutado en 2004, mientras que el rojizo sería el medieval. El sombreado representa los restos de antiguas estructuras localizadas en la prospección arqueológica realizada con motivo de la construcción del nuevo camino. En la zona norte se han trazado los lienzos de muralla de la fortaleza Baja que entestan con el macizo rocoso. Plano de los autores. 


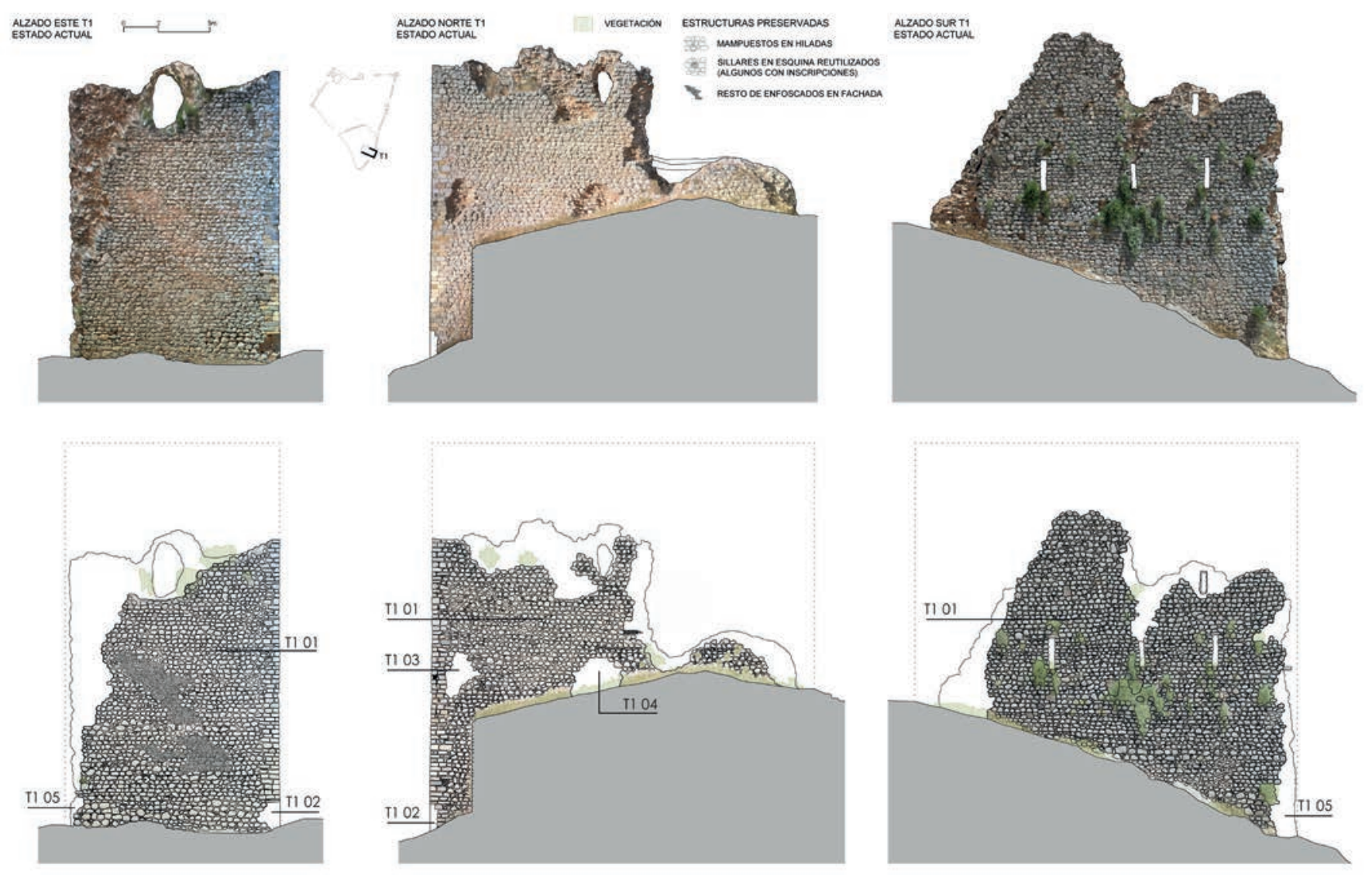

Fig. 14. Levantamiento fotogramétrico de la torre del homenaje del castillo de La Peña de Martos (la fila de arriba contiene las ortofotografías y la de abajo el delineado de los elementos conservados). Planos de los autores.

recinto amurallado, que, o bien son de planta circular, o cuentan con las esquinas curvas, hecho que también está en la torre del homenaje del castillo de Víboras (Fig. 7).

El diseño de la principal torre del castillo de La Peña es bastante compacto, contando con ventanas rasgadas no conformadas con sillares, con forma abocinada hacia el interior. Las mejor conservadas están en el alzado sur, donde se puede observar tres aspilleras y los restos de una cuarta dispuesta a un nivel superior. En los demás alzados también estuvieron presentes, aunque su contorno se haya muy desfigurado. Cuentan con unas dimensiones de aproximadamente $1,80 \times 0,40 \mathrm{~m}$. Por su ubicación y posición, la función de estos huecos era la de iluminar y ventilar las estancias, siendo las emplazadas hacia el flanco este las únicas que podrían permitir un uso defensivo.

Empotrado en el paramento del alzado norte y a la altura del suelo del primer nivel de la torre, se ha conservado una cavidad de sección cuadrada que podría haber formado parte del sistema de acceso. Está ejecutada en ladrillo, destacando la erosión que se aprecia en la base inferior, debido posiblemente al desgaste provocado por un elemento circular. Se encuentra a ras del suelo del primer nivel y podría haber estado vinculada a un eje horizontal del sistema de puerta basculante de entrada a la torre. El acceso a esta plataforma abatible tendría que realizarse con medios auxiliares, tales como ménsulas empotradas en el muro, rampas y/o escaleras, hecho que puede apreciarse en los huecos alineados en diagonal de la torre del homenaje del castillo de Víboras. En este último caso se ha conservado un espolón de mampostería en su esquina noroeste, junto al arranque de estos huecos, por lo que en las inmediaciones de la torre del homenaje del castillo de La Peña pudieron existir estructuras anexas vinculadas a este sistema de acceso, como parecen apuntar los restos arqueológicos que se vislumbran cerca de su esquina nordeste.

Esta torre del homenaje evidencia haber tenido al menos tres salas superpuestas, conservándose una estancia colmatada por escombros bajo el nivel accesible actualmente. La inferior está compartimentada, lo que podría estar en consonancia con los indicios de división espacial en los niveles superiores de estas grandes salas 
longitudinales de más de $15 \mathrm{~m}$ de longitud, cubiertas con bóveda de cañón.

Diversos autores atribuyen a la estancia inferior el uso de aljibe. Sin embargo, este espacio se encontraba iluminado, puesto que las tres ventanas rasgadas conservadas en el alzado sur están asociadas a este nivel. Por ello en esta planta se encontrarían otras dependencias de la torre, existiendo aún la posibilidad de que un aljibe hubiese sido dispuesto en un nivel inferior a este, quedando así la torre organizada en cuatro plantas (Fig. 15, arriba).

En las estructuras emergentes no se aprecian evidencias de las escaleras que permitiesen realizar las conexiones verticales entre los diferentes niveles. Probablemente, estas podrían haber estado empotradas en los mismos, tal y como sucede en la mejor preservada torre del homenaje del castillo de Víboras y como parecen que fueron reflejadas en uno de los dibujos realizados en la década de 1980 por Francisco Cerezo Moreno (Fig. 12, derecha).
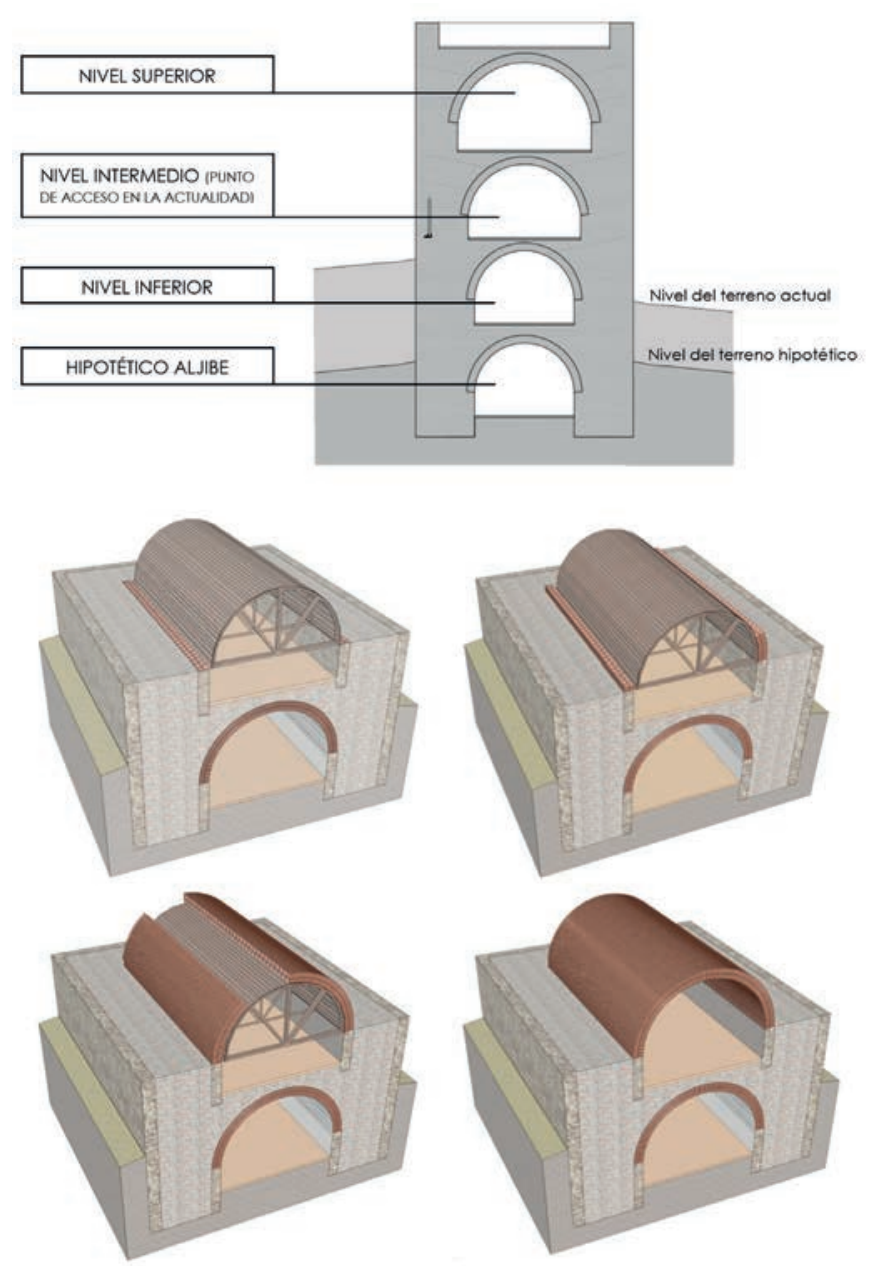

Fig. 15. Esquema con los diferentes niveles de la torre del homenaje (arriba) y secuencia constructiva de las bóvedas (abajo). Dibujos de los autores.
En cuanto al nivel superior, no quedan restos que permitan una completa interpretación del espacio. Los muros de la torre van disminuyendo en sección, pasando de los 2,60 $\mathrm{m}$ de espesor del nivel intermedio a los 2 $\mathrm{m}$ en la planta más alta, de la que quedan restos de los arranques de las bóvedas de ladrillo y de posibles muros o arcos fajones que, además de rigidizarla, podrían estar en relación con la compartimentación del espacio de la sala superior. La coronación de la torre del homenaje se ha perdido completamente, pudiendo haber existido un espacio aterrazado sobre el nivel superior.

Las bóvedas se encuentran ejecutadas con dos hiladas de ladrillo dispuestas a soga, que quedarían enrasadas con la cara interna de los muros. Dadas sus dimensiones, para su construcción debió de emplearse una cimbra que le sirviera de apoyo y que sería retirada una vez finalizara el proceso (Fig. 15, abajo). El trazado de las bóvedas sería continuo, quedando interrumpido únicamente por las ventanas rasgadas colocadas en los alzados norte y sur, que por su posición debieron de quedar englobadas en estas. Esta técnica es observable también en los tragaluces de las caballerizas del cercano castillo de Alcaudete.

Esta torre pudo haber alcanzado los $20 \mathrm{~m}$ de altura sobre la rasante del alzado este, con tres o cuatro niveles cubiertos con largas bóvedas de cañón que pudieron alojar en su interior distintas estancias para albergar el programa de necesidades demandado por la Orden de Calatrava.

\subsection{Lienzos de muralla LO, L1 y torre T2}

El lienzo L0 es el único que subsiste del perímetro amurallado del recinto superior en la vertiente sureste. Destaca la aparición de un quiebro en su trazado, aprovechando el sustrato rocoso y actuando a modo de cremallera, sobresaliendo como el elemento defensivo principal que se prolongaría en el frente oeste (Fig. 16).

Este muro no se encuentra trabado con la torre del homenaje. Esto podría estar indicando la existencia de diferentes momentos constructivos y ha podido ocasionar el derrumbe de parte de su trazado, debido a la falta de arriostramiento.

La muralla L1 se sitúa al norte de la torre del homenaje, delimitando el contorno del recinto superior hasta alcanzar el foso. Este también se adosa sin enlazarse a la cara norte de la torre del homenaje. Está actuando como contención de una gran acumulación de material procedente de los derrumbes, presentando un desnivel de más de $5 \mathrm{~m}$ entre el alzado interior y el exterior. 

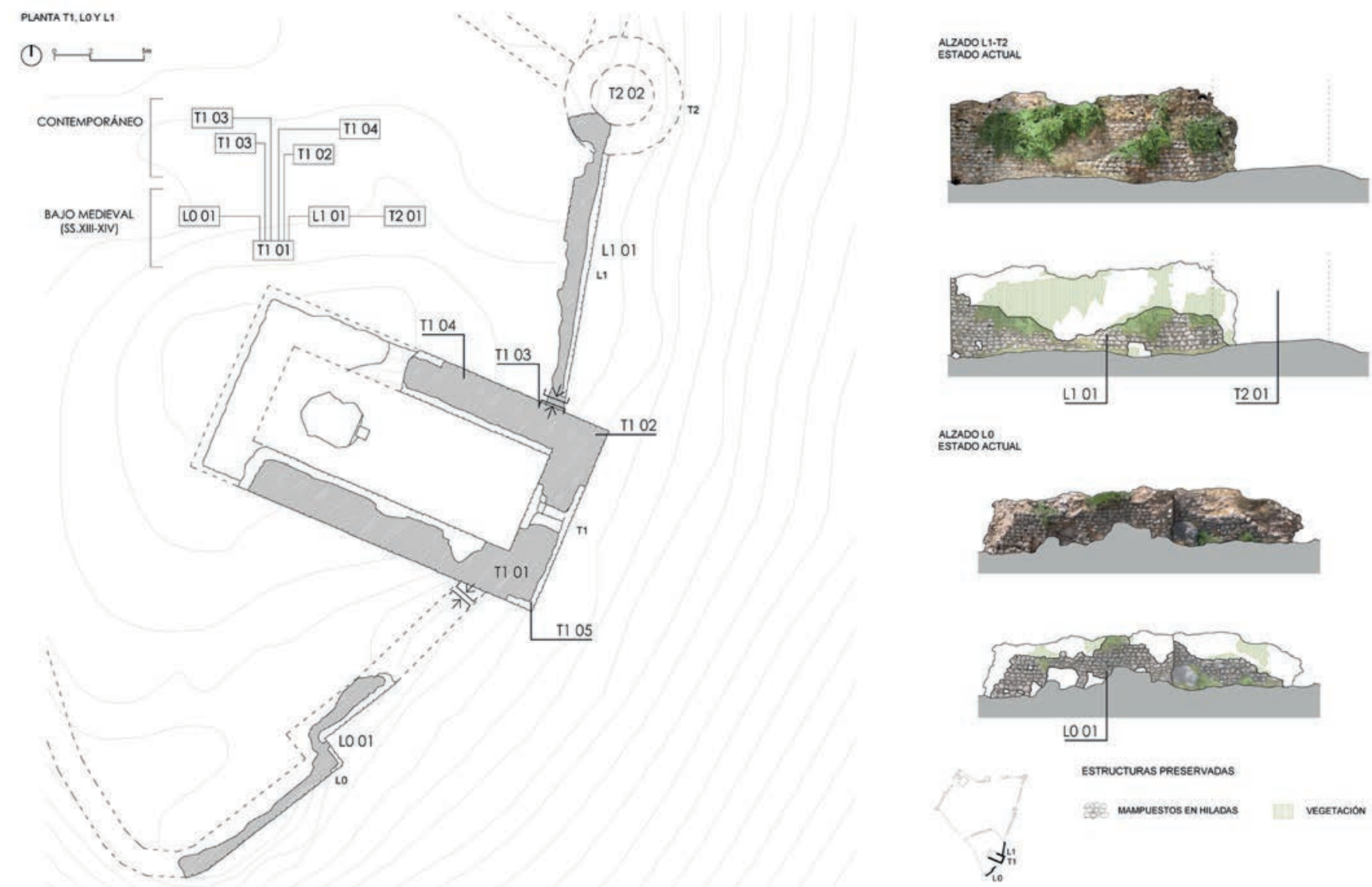

ALZADOLLO
ESTADO ACTUAL
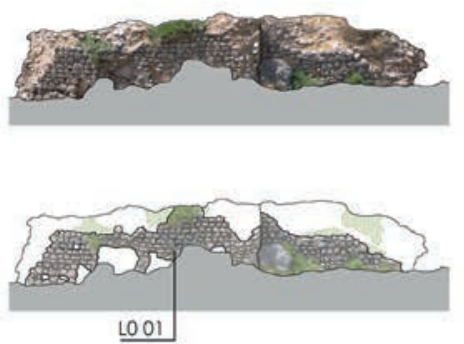

ESTRUCTURAS PRESERVADAS

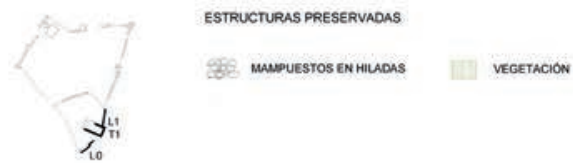

Fig. 16. Planta y alzado de los lienzos L0 y L1, adosados a la torre del homenaje. Planos de los autores.

La torre circular T2 ha resultado clave para conocer las fases evolutivas del castillo de La Peña. Se encuentra prácticamente desaparecida, por lo que las descripciones de la fortaleza no se han hecho eco de su presencia. Con todo, aún se pueden ver suficientes mampuestos en el terreno para evidenciar su forma curva, con un diámetro exterior que pudo alcanzar los $7 \mathrm{~m}$. En torno a esta torre circular pudo haber existido un sistema de control para el acceso al recinto superior. En ella convergen el lienzo de muralla L2, proveniente del recinto inferior, y el muro al sur del foso para proteger el recinto superior.

Los restos de ladrillo existentes a su alrededor sugieren la posibilidad de que la estancia interior pudo haber estado cubierta por una cúpula de este material. Se conservan además indicios de las jambas que delimitarían el acceso desde el perímetro amurallado en torno a la torre del homenaje.

\subsection{Lienzo de muralla L2 y torre- puerta P1}

El lienzo de muralla L2 tiene un trazado rectilíneo y discurre sobre el lado este de la fortaleza, hasta alcanzar los restos de una torre que habría albergado una puerta del recinto inferior (Fig. 17). Este muro cuenta con una cota que alcanza los $4 \mathrm{~m}$ de altura sobre la rasante y un espesor de 1,60 m, al igual que la mayor parte de los restantes lienzos. En su relleno interior se puede observar la colocación aleatoria de piedras de mayor tamaño, que vendrían a arriostrar y a dar mayor cohesión al lienzo de muralla. En el alzado exterior la mampostería se dispone en hiladas, con una diferencia de tamaño entre las superiores y las inferiores, habiéndose colocado piedras grandes que en algunos casos rompen la linealidad. El sustrato rocoso sobre el que se cimenta el muro aflora en varios puntos, introduciéndose mampuestos para regularizar estos desniveles, al igual que sucede en la torre del homenaje. A la altura aproximada de 2,60 m sobre la rasante, se observa una hilada de regularización a partir de la cual se produce un detrimento en el tamaño de los mampuestos utilizados, volviendo a las dimensiones estándares entre los 20 y $40 \mathrm{~cm}$.

El alzado interior presenta unas características similares al exterior, apreciándose algunas irregularidades en las hiladas más cercanas al foso y a otras zonas puntuales 

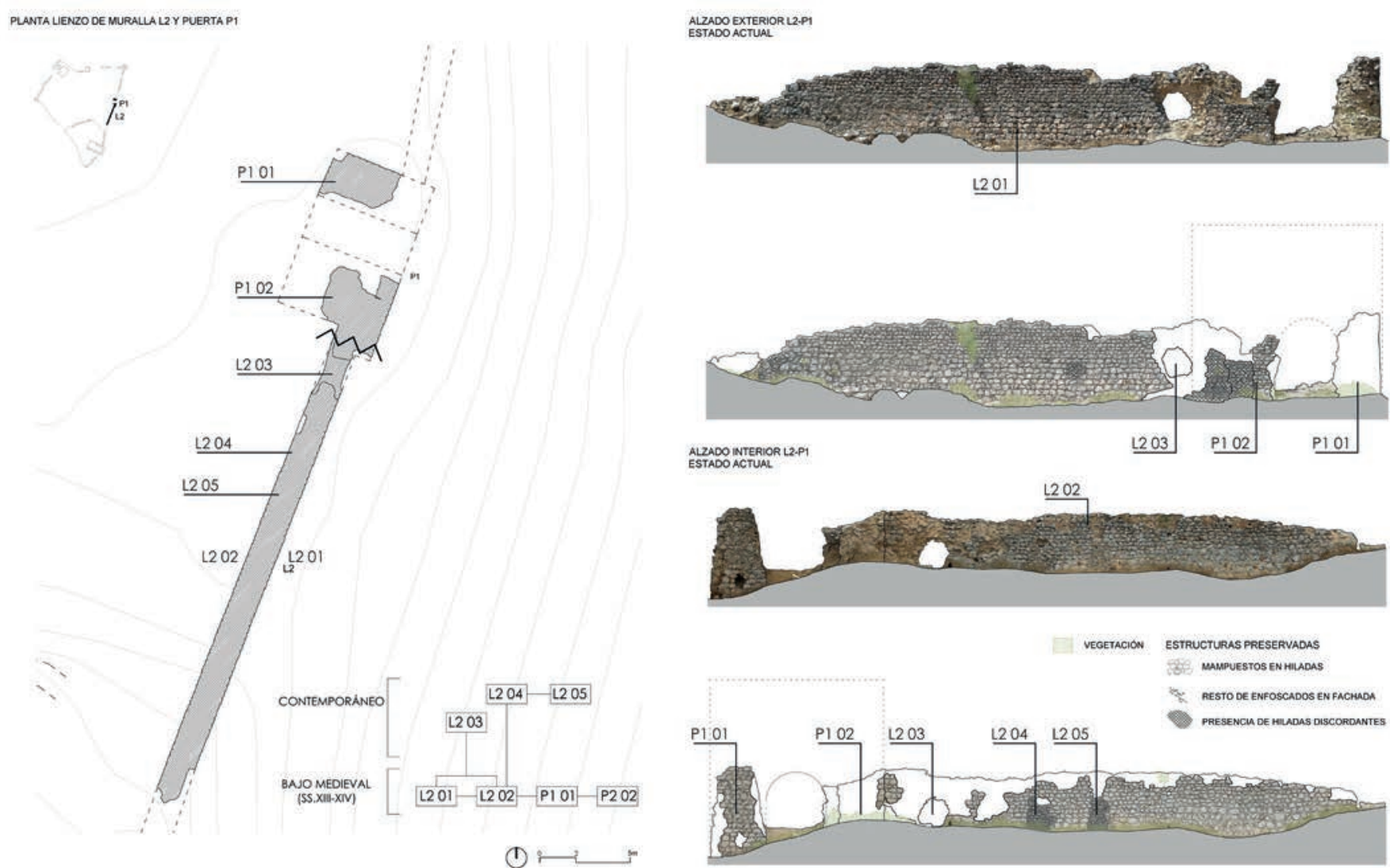

Fig. 17. Planta y alzado actual del lienzo L2 y la torre-puerta P1. Planos de los autores.

del lienzo donde se produce una ruptura en el trazado, existiendo restos de morteros que serían posteriores a la construcción inicial. Estas anomalías coinciden con huellas de otros muros o estructuras desaparecidos que lo habrían acometido.

Al alcanzar este lienzo a la torre-puerta de entrada (P1), se produce un ensanchamiento en su sección, enmarcándose en el planteamiento de un acceso al recinto inferior del castillo. En el alzado exterior se aprecian piedras dispuestas para encajar la rosca de un arco. Presentan un trazado rectangular, de aproximadamente $10 \times 6,30$ $\mathrm{m}$, sobresaliendo $1 \mathrm{~m}$ de la rasante del lienzo de muralla.

En el alzado frontal existen irregularidades en los morteros, que presentan una coloración más rojiza, y en las hiladas, que muestran la colocación anárquica de mampuestos indicando intervenciones posteriores. Los visitadores de la orden ya dejaron constancia de las necesidades de reparaciones en la puerta de la fortaleza.

Se observa la presencia de sillares y piedras talladas embutidas en el muro tras la jamba sur, que podrían haber estado vinculadas a las guías de un rastrillo. La torre-puerta presentaba al menos una planta por encima del nivel de paso, dados los restos que subsisten en el flanco norte, donde aún se constata la cara interior de los muros con un espesor de $1,80 \mathrm{~m}$, que sería excesivo para un pretil o un almenado de cubierta. Esta estancia parece quedar señalada en las puertas representadas en los grabados de la fortaleza de La Peña publicados en 1579 por Diego de Villalta (Fig. 9).

\subsection{Lienzo de muralla L3 y torre circular T3}

Sería el que discurre de norte a sur entre la torre-puerta de entrada (P1) y la torre circular (T3), situada en el extremo noreste (Fig. 4). Es uno de los tramos peor conservados, con muros de $1,60 \mathrm{~m}$ de espesor que se elevan poco más de $0,50 \mathrm{~m}$ sobre el nivel del terreno. Es el tramo con mayor longitud de la fortaleza, superando los 40 $\mathrm{m}$, dimensiones poco habituales en las fortalezas de esta época. Este hecho ha podido ser el causante de su mal estado de conservación, al no contar aparentemente con ningún elemento intermedio que ejerciese de contrafuerte, salvo que haya quedado sepultado por los derrumbes.

La torre circular T3 se encuentra en el extremo noreste del recinto (Fig. 18, derecha), en la esquina en la que 
convergen los lienzos L3 y L4. Es la única torre hueca del castillo de la que se conserva parte de su alzado. Esta se proyecta hacia el exterior de ángulo que se produce en la muralla, quedando a medio camino entre un cubo de flanqueo y una torre albarrana, aunque no llega a separarse de los lienzos murarios. En su interior hubo al menos un espacio cubierto conectado con el recinto inferior de la fortaleza, conservándose aún los restos del ladrillo que conformarían el hueco abovedado de acceso. Sus dimensiones son similares a las de la desaparecida $\mathrm{T} 2$, con un diámetro de $6,50 \mathrm{~m}$ y unos muros de $1,50 \mathrm{~m}$ de espesor, ligeramente inferiores a los del resto del recinto. El espacio interior fue cubierto con una bóveda semiesférica de ladrillo de $14 \times 28 \times 4 \mathrm{~cm}$, que podría haber alcanzado los 1,60 m sobre el nivel del arranque. Su disposición se realizaría de forma concéntrica y presenta similitudes con la pequeña cúpula que cubre la escalera de subida a la sala superior del cercano molino fortificado del Cubo, en el término municipal de Torredonjimeno. En el interior de los muros circulares se conservan pequeñas oquedades con diámetros de 8 y $12 \mathrm{~cm}$, que aparecen de forma repetida a lo largo del perímetro circular. Podrían estar relacionadas con un andamiaje puntual o como tirantes de refuerzo para contrarrestar los empujes de la bóveda, hecho que ha sido constatado en otras torres cubiertas con estas estructuras, tal y como sucede en la de Montalveche (Vélez-Rubio). Destaca el mayor uso del ladrillo como material para el ripiado y la aparición de fragmentos de tejas para tal fin, hecho que será recurrente a lo largo del alzado norte. En esta torre se pueden apreciar muestras del revestimiento que debió tener la fortaleza, siendo el punto donde este se muestra con mayor claridad de todo el conjunto.

Sobre esta bóveda cabe la posibilidad de que hubiera una sala superior. No quedan vestigios de elementos de comunicación vertical entre estos espacios, que, de haber existido, debieron ser de escasa entidad debido a las pequeñas dimensiones del aposento. Lo más probable es que no hubiera una comunicación directa entre ellos, y que a la parte superior se accediera por el exterior o a través de los caminos de ronda que discurrirían sobre los lienzos de muralla, tal y como parece apreciarse en el dibujo realizado por Francisco Cerezo Moreno en la década de 1980 (Fig. 12, centro).

\subsection{Lienzo de muralla L4}

Se sitúa entre la torre circular T3 y la cuadrangular T4 (Fig. 18, centro). Está emplazado en la cara norte del recinto y los restos que aún quedan presentan un buen estado de conservación.

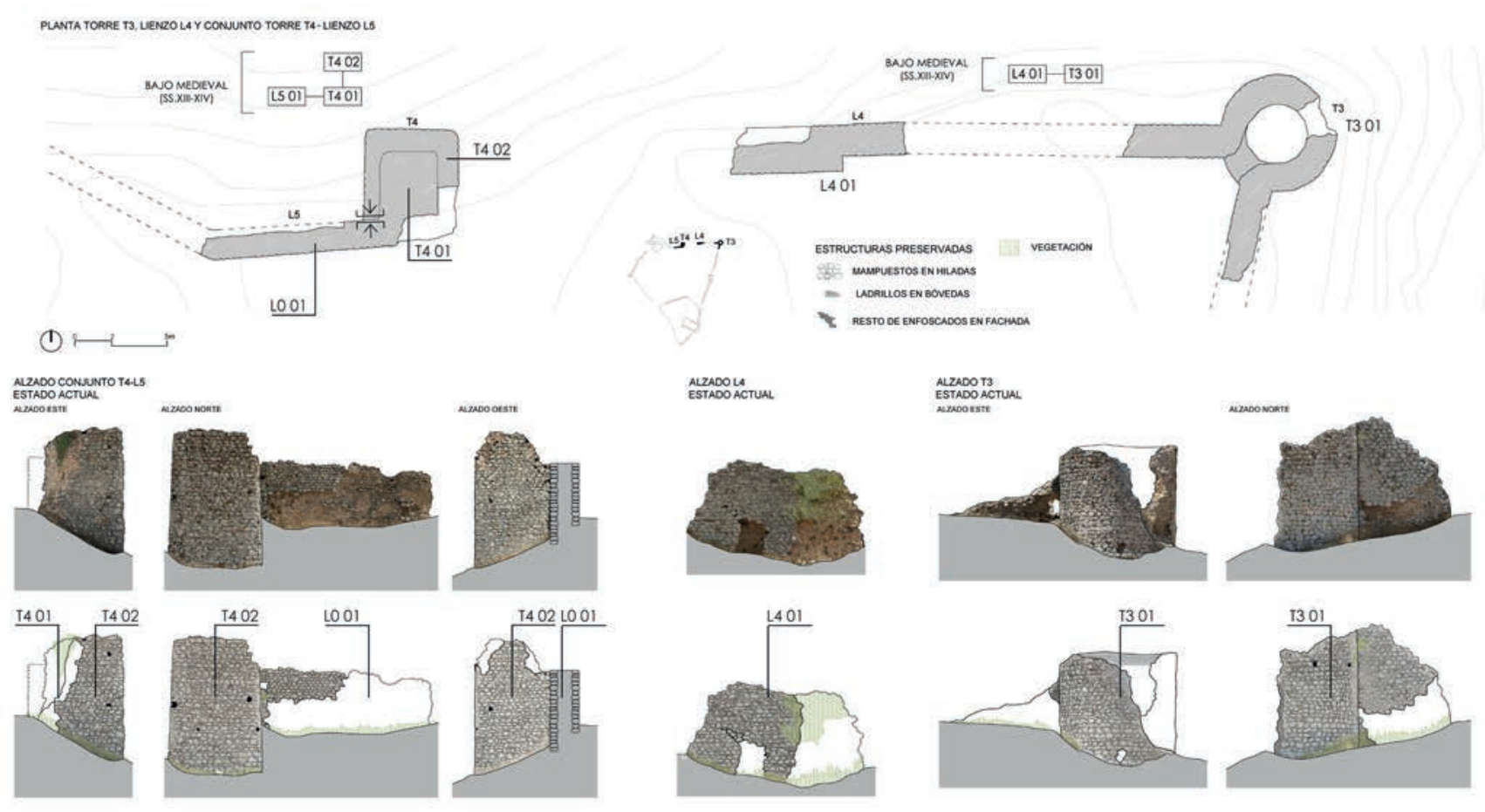

Fig. 18. Planta y alzados de las estructuras murarias y torres conservadas en el sector noreste del castillo de La Peña. Los cuatro de la derecha a la torre circular T3, los dos centrales al lienzo L4 y los seis alzados de la izquierda corresponden a la torre cuadrangular T4. Planos de los autores. 
Al igual que sucede en la torre T3, en el aparejo de la fábrica existen abundantes restos de tejas y ladrillos. Esto podría indicar que en sus alrededores debieron de existir otras construcciones arruinadas, de las que pudieron haberse aprovechado dichos materiales. Presenta un trazado irregular, observándose un engrosamiento en la parte central del muro, desde los 1,60 m, hasta los 2,20 m. Este no es el resultado de un añadido posterior, sino que derivaría de las necesidades de reforzar este tramo de muralla, que presenta una longitud de $47 \mathrm{~m}$. El peralte solamente es apreciable en su alzado interior, mostrando hacia el exterior un paramento continuo.

$\mathrm{Su}$ trazado discurriría en dirección al siguiente torreón del recinto (T4), pero no se aprecia en superficie su continuidad en suelo. En este punto podrían haber existido otro acceso al recinto inferior de la fortaleza que se comunicase directamente con la Villa de Martos. Esta hipótesis tendría sentido en tanto que, desde este alzado norte, se tiene contacto visual directo con la fortaleza Baja. Tal vez la etimología del barrio de El Portillo, situado en el contacto de Martos con La Peña, pudiese estar en relación con una posible conexión entre ambas fortificaciones a través de esta vertiente septentrional. Además, estaría en consonancia con los grabados históricos del siglo XVI, que ubicaban una torre-puerta con cierta monumentalidad y como símbolo de poder en este frente de la fortaleza.

\subsection{Torre cuadrada $\mathrm{T} 4$ y lienzo de muralla L5}

Esta torre se ubica en la parte central del alzado norte de la fortaleza, estando entre los lienzos de muralla L4 y el L5 (Fig. 18, izquierda), dirigiéndose este último en dirección al aljibe en sentido oeste.

La torre T4 es un elemento singular en el diseño de la fortaleza, alzándose como un bastión que presenta ciertas peculiaridades constructivas. En ella se constata el recrecido de una primitiva torre de menor envergadura, que algunas descripciones recientes del castillo mencionan como los vestigios de una fortaleza andalusí. Sin embargo, la técnica constructiva del torreón interior es similar a los del resto de la fortaleza calatrava. El recrecido sería el resultado de otra fase, motivada por la necesidad de reforzar este elemento o bien por su posible vinculación con la puerta representada en los grabados del siglo XVI. Las esquinas que definen la fábrica más externa son redondeadas, hecho que podría estar en relación con las adaptaciones poliorcéticas del siglo XIV a la incipiente artillería, teniendo constancia de que en el año 1325 se produjo un asalto con el uso de la pólvora. El desarrollo de esquinas curvadas también es apreciable en el muro L6 que confina al aljibe.

$\mathrm{Al}$ igual que en el lienzo L4, en la torre T4 también se aprecian perforaciones de entre 8 y $12 \mathrm{~cm}$ de diámetro en el interior del muro de mampostería que la reviste interiormente. Estas se introducen en la sección del recrecimiento de dicha torre, por lo que podrían responder a la necesidad de arriostramiento entre ambas estructuras. Al analizar la trayectoria de los orificios, se puede comprobar que están dispuestos en sentido diagonal, lo que consigue una mayor superficie de contacto entre el elemento pasante y la estructura preexistente.

El tramo de muralla L5 es el que presenta mayor superficie de material desplomado de todo el castillo. En su trazado destaca el quiebro de unos $20^{\circ}$ hacia el norte que se aprecia en el punto más occidental del paño conservado, donde se ha producido la rotura. El trazado de muralla puede seguirse por medio de varios vestigios sobre la rasante del suelo, continuando en dirección oeste hasta abrazar al aljibe por medio del lienzo L6.

\subsection{Lienzo de muralla L6, aljibe y alberca}

En el extremo inferior y más septentrional del recinto interior se encuentran los restos de las estructuras relacionadas con el sistema de abastecimiento de agua al menos al recinto inferior de la fortaleza (Fig. 19).

De La Peña surgen manantiales como el de El Sapillo o el de Los Charcones, que han posibilitado el abastecimiento a la población de Martos, pero en su cima no existen surgencias de agua ni tampoco se ha constatado la excavación de pozos. Esta razón justificaría la construcción de depósitos para la recolección de pluviales y su almacenamiento en la cota más baja del recinto, hacia donde se podrían conducir las escorrentías. Los restos conservados están formados por una alberca, relacionada a su vez con un aljibe adosado a la muralla.

La fortaleza de La Peña es el único exponente en los castillos calatravos del entorno que cuenta con una alberca conectada a un aljibe, sirviendo este elemento como un decantador del agua antes de su almacenamiento en 

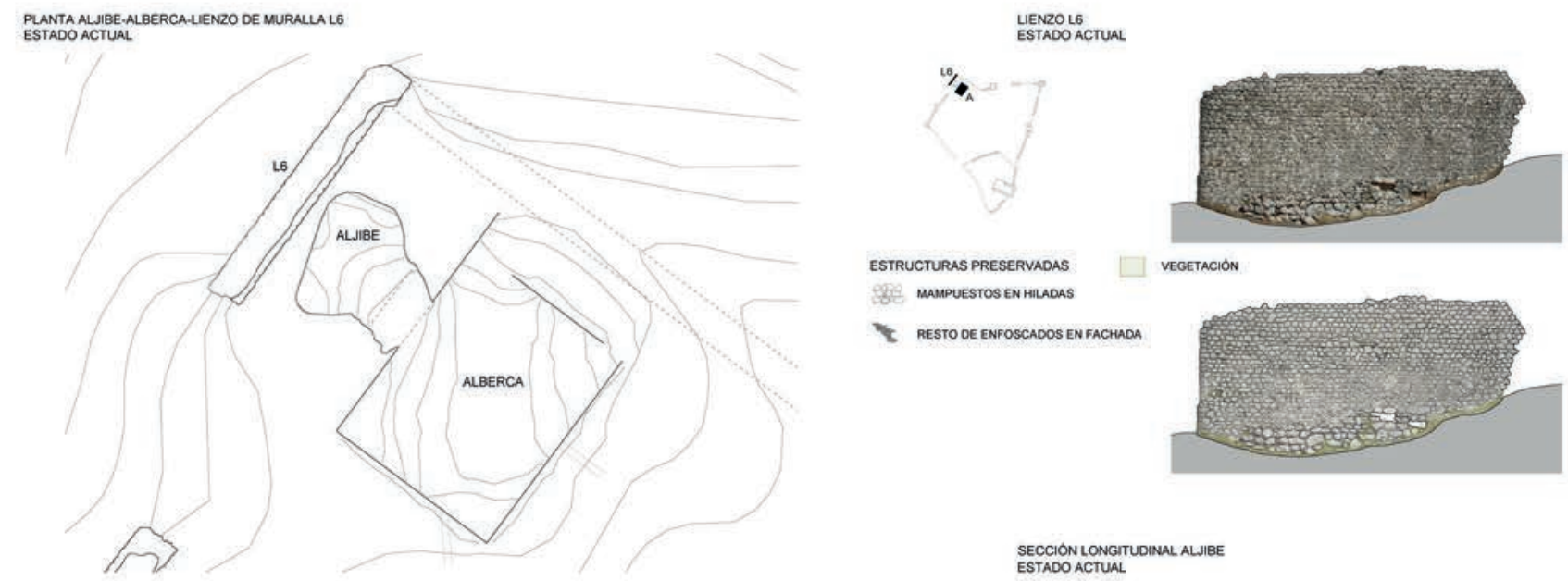

PLANTA ALIIBE-ALBERCA-LIENZO DE MURALLA LG NIVEL INFERIOR

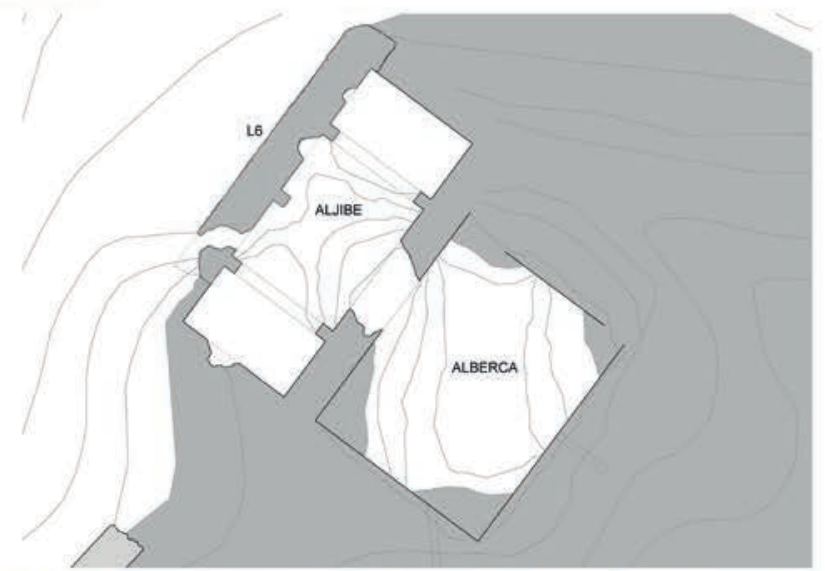
SECCIÓN LONGITUDINAL ALIBE
ESTADO ACTUAL

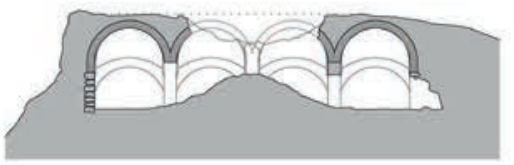
SECCION TRANSVERSAL CONJUNTO ALIIBE-ALBERCA ESTADOACTUAL

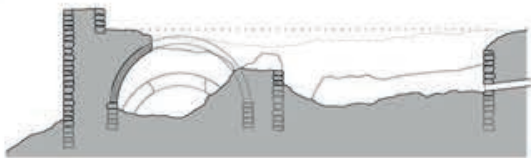

HIPOTESIS DE
FUNCIONAMIENTO

(1)
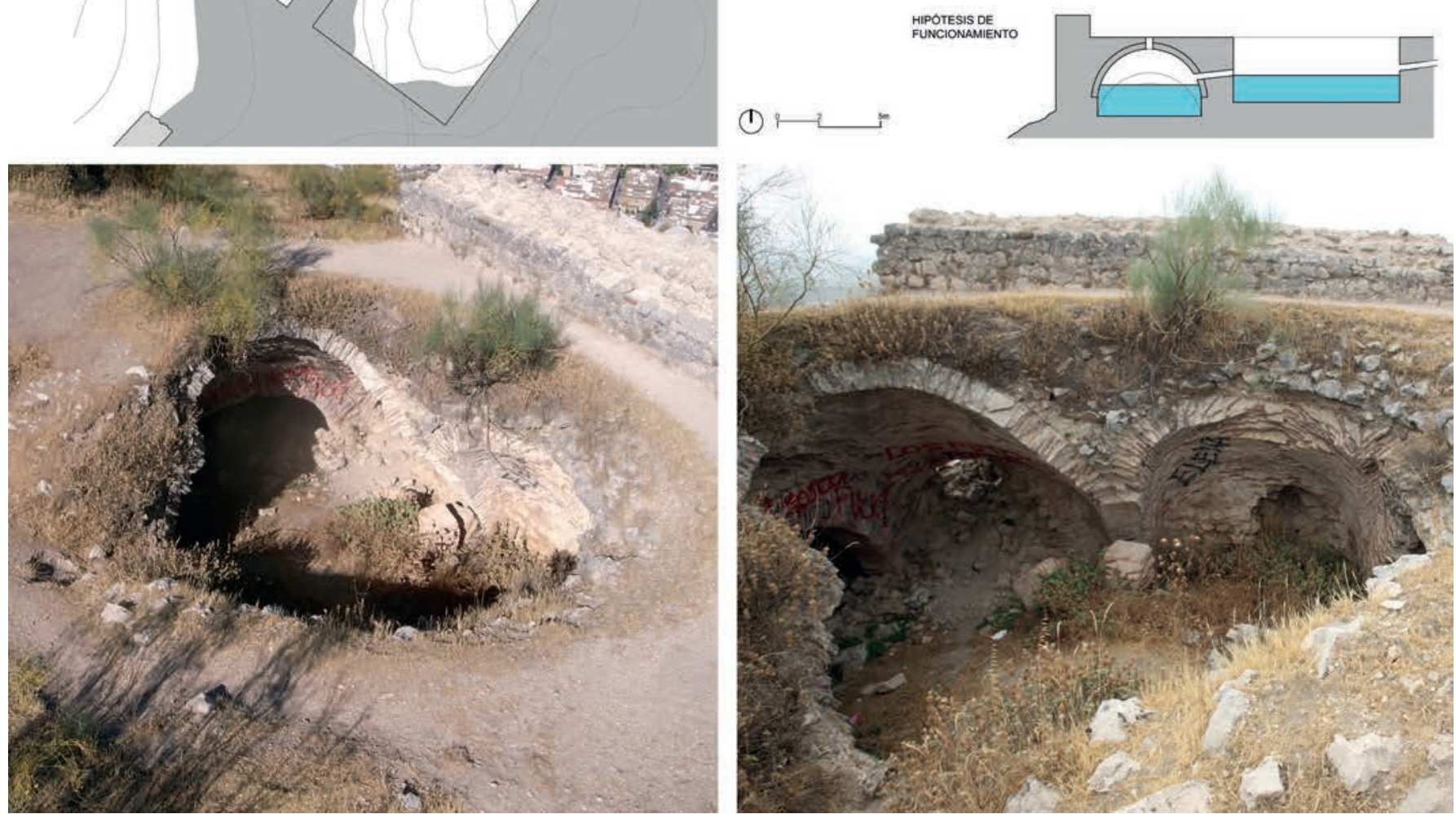

Fig. 19. Planta, alzados y secciones de las estructuras murarias conservadas en torno al aljibe y la alberca situada en el extremo septentrional del recinto inferior del castillo de La Peña. Planos y fotografías del aljibe de los autores. 
la cisterna. La primera cuenta con unas dimensiones de $8 \times 11 \mathrm{~m}$ y muros de mampostería, revestidos con una capa de mortero hidrófugo. En su parte más elevada se localizan dos orificios de entrada de agua. Están ejecutados en mampostería y presumiblemente quedarían conectados con una red de recogida de escorrentía de lluvia, pues se orientan hacia los sectores este y oeste del recinto inferior. En la parte oriental de la alberca se aprecian los restos de una plataforma de mampostería que debió de tener unas escaleras de bajada a la lámina de agua.

El líquido pasaría al aljibe por medio de una conducción, donde se almacenaría para su posterior extracción por un brocal, posiblemente en algunas de las bóvedas más centrales, que son las que presentan una mayor rotura. Sobre sus tres naves se dispuso una terraza asomada a la muralla.

Para la construcción del aljibe y la alberca debió de aprovecharse una vaguada natural, quedando confinada por el lienzo L6. Este muro es el único que presenta un zócalo, que podría provenir de la necesidad de crear un basamento que sirviera de regularización para la construcción del aljibe.

Esta cisterna presenta planta rectangular y queda dividida en cuatro naves que se encuentran separadas por tres arcos rebajados de ladrillo. Están cubiertas por bóvedas del mismo material de $29 \mathrm{~cm}$ de soga aparejados a canto, que, por las aristas que presentan, podrían considerarse como esquifadas, resultantes de la intersección de dos cañones provenientes de los lados laterales y frontales. En su construcción no se recurrió al uso de cimbras, al igual que en muchas de las bóvedas nazaríes construidas en torres (Almagro y Orihuela 2013). Los arcos de medio punto que dividen las naves tienen un espesor de $45 \mathrm{~cm}$ y están elaborados con dos ladrillos colocados a soga y tizón. Por su extradós, estas bóvedas se rellenarían de mampuestos hasta alcanzar la cota del nivel superior. Todo el interior se encontraría revestido con un enfoscado de cal para impermeabilizar y pintura a la almagra para evitar filtraciones y la posible contaminación del agua.

El aspecto de este depósito es muy tosco y se pueden apreciar irregularidades en su trazado, con una curvatura más suave en su parte inferior que en la superior, lo que pudo deberse a una posible corrección del aparejo durante el proceso de puesta en obra. En los castillos del entorno, tales como el de Santa Catalina en Jaén o el de Alcaudete, existen ejemplos de aljibes cubiertos con bóvedas de ladrillo, aunque ejecutadas de una forma mucho más regular.

Exteriormente el aljibe estaría protegido por el lienzo L6, siendo uno de los mejor conservados de toda la fortaleza. Esta muralla presenta un espesor superior al resto, alcanzado los 2,40 m, debido a la necesidad de contener la presión hidrostática. En su parte superior la sección se reduce hasta alcanzar 1,60 m, conservándose restos que apenas se elevan $1 \mathrm{~m}$ sobre la rasante.

Los restos del trazado de la muralla se encuentran muy deteriorados en su continuidad hacia el lienzo L7, no pudiéndose establecer con exactitud el recorrido que este presentaría, que pudo estar resuelta con una ligera curvatura, o bien contorneando la nave más oriental del aljibe. Esta última posibilidad tendría más sentido, configurándose en torno a este punto un contundente bastión defensivo que reforzaría el flanco noroeste de la fortaleza.

La esquina que se conserva al este de esta estructura también presenta un acabado redondeado, proyectado ya en el diseño original. Esto podría indicar que en el periodo de construcción de este recinto inferior ya se tenía constancia del uso de artillería, lo que podría estar apuntando una fecha de construcción del recinto inferior en la primera mitad del siglo XIV.

\subsection{Lienzos de muralla $L 7, L 8$ y torreones T5, T6}

Este tramo del recinto amurallado discurre entre la esquina noroeste del aljibe y la torre T6, estructura semicircular adosada a la muralla (Fig. 20), en un punto del trazado de los lienzos de muralla en el que se produce un giro en dirección al "mal vecino".

Los lienzos L7 y L8 presentan similares características, con un trazado regular, sin apreciarse alteraciones. La distribución de las hiladas se prolonga hasta la torre T6, donde la continuidad de los lienzos comienza a desaparecer, quedando solamente vestigios y restos de morteros que insinúan la existencia de un pretil o una estructura de escasa importancia por lo abrupto del terreno.

Los torreones presentan una sección semicircular y maciza, siendo la única muestra de esta tipología en el recinto. La torre $\mathrm{T} 5$ no se encontraba trabada con el lienzo de muralla, lo que implica que esta actuaría a modo de contrafuerte, acortando la distancia de los lienzos que, de no ser así, estaría por encima de los 50 


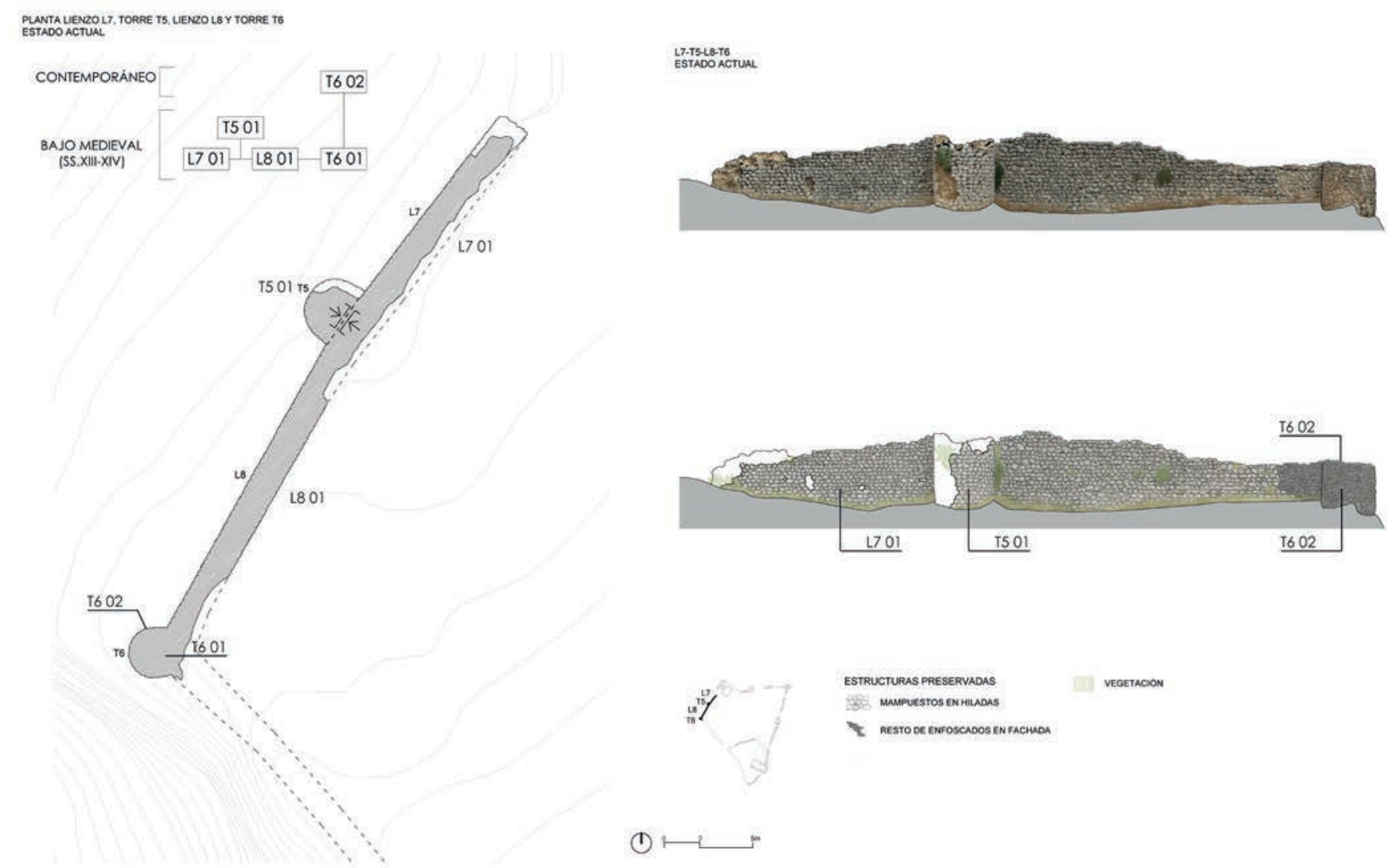

Fig. 20. Planta y alzados de las estructuras murarias y torres conservadas en el sector noroeste del castillo de La Peña. Planos de los autores.

m. Por el contrario, la torre T6 sí presenta evidencias de encontrarse enlazada con el trazado murario.

\section{MATERIALES Y TÉCNICAS CONSTRUCTIVAS}

En el recinto amurallado de la fortaleza Baja de Martos quedan muestras de construcción en tapial, presente en buena parte de las edificaciones almorávides y almohades (Orihuela y Castillo 2012; Gallego et al. 2016). En las fortificaciones que fueron reparadas, rehechas o construidas ex novo por la Orden de Calatrava en sus encomiendas del Campo de Calatrava desde las últimas décadas del siglo XII (Aranda et al. 2016) y en el partido de Martos a partir del segundo tercio del siglo XIII (Eslava 1984), se impuso preferentemente el uso de la mampostería careada en hiladas horizontales, a menudo enripiadas y con sillares escuadrados en las esquinas (reutilizados o tallados expresamente). Esta técnica constructiva también se extendería al reino nazarí de Granada en los siglos XIV y XV (García-Pulido et al., 2016a, 2016b).
Pese a que las fuentes parecen apuntar la existencia de estructuras militares en La Peña previas a las construcciones de la Orden de Calatrava, no quedan evidencias de estas. Todos los restos emergentes conservados en la fortaleza responden a unos mismos principios constructivos, sin observarse grandes diferencias en los aparejos de piedra, por lo que el castillo calatravo habría supuesto un hiato con todo lo anterior, quedando las estructuras previas amortizadas o enmascaradas (Fig. 21). Un paralelo podríamos encontrarlo en algunas fortalezas del Campo de Calatrava tales como las de Aznarón, Miraflores, Caracuel, Calatrava la Nueva, Salvatierra, Bolaños, Malagón (Aranda et al. 2016: 46), donde no solo se repararon y forraron con este sistema construcciones andalusíes realizadas en tapial, sino que se sustituyeron completamente por otra concepción poliorcética en la que destacaban torres del homenaje, cubos, bestorres, murallas en cremallera, torres-puerta con rocas más duras en los arcos, así como almenas de mampostería con tendencia a la forma cúbica, con el remate biselado hacia el exterior y con aspilleras bajo los merlones.

La Peña es un sólido rocoso donde abunda la caliza dolomítica, lo que la convierte en una cantera natural de 

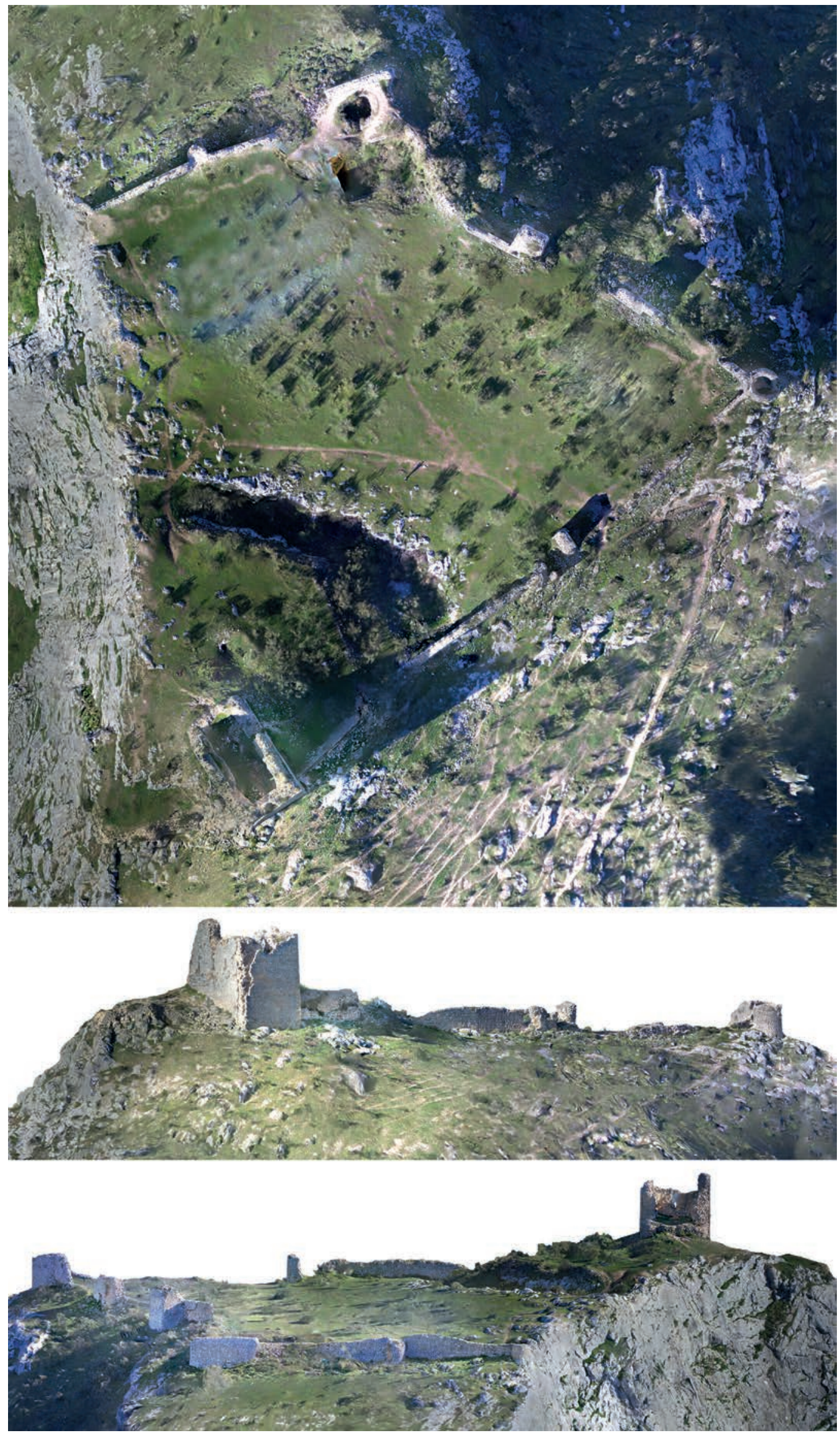

Fig. 21. Ortofotografías con la planta y alzados este y norte del castillo de La Peña. Fotografías y ortofotografías de los autores. 
donde obtener el material constructivo y el aglomerante, siendo esta piedra la que impera de forma predominante en toda la fortaleza. Fue extraída del foso y utilizada mayoritariamente como mampostería sin labrar, con la superficie más plana para dar cara al exterior, rellenado los huecos con abundante ripio. El tamaño de estas piedras es variable, oscilando entre los 20 y $40 \mathrm{~cm}$ en función de su localización. También aparecen pequeños fragmentos de piedra arenisca reutilizada, por lo general con un aspecto mucho más regular, y trozos de teja y ladrillo, sobre todo en determinados lienzos de la zona nordeste del recinto.

La mampostería se dispone en hiladas más o menos regulares, ripiadas para mantener su horizontalidad. En el relleno interior se insertaron también piedras de mayor tamaño que servían para arriostrar y dar mayor consistencia. La sección de los lienzos de muralla tiende a ser constante, teniendo un espesor de 1,60 m. Las dimensiones de las hojas exteriores oscilan entre los 20 y $25 \mathrm{~cm}$, con lo que el relleno interior llega a alcanzar los $1,20 \mathrm{~m}$. Puntualmente, se aprecian refuerzos que alcanzan los 2,40 $\mathrm{m}$ de espesor.

En algunos lienzos del recinto se reconoce la presencia de mechinales para maderas pasantes, con sección circular de diámetro entre los 8 y $12 \mathrm{~cm}$, que habrían sido taponados con una piedra en el exterior, lo que a priori parecería apuntar al uso de mampostería encofrada ${ }^{12}$.

Sin embargo, el estado que presenta el castillo de La Peña permite estudiar el relleno interior de los muros en los puntos en los que la cara se ha desprendido, como ocurre en el lienzo L4. La ausencia de una disposición regular y continua en estas oquedades manifiesta que en su origen no se emplearon encofrados, sino que la mampostería se colocaría careada en hiladas, siendo los orificios las huellas de elementos auxiliares para la construcción o refuerzos de atirantamiento y/o trabazón.

Las fábricas encofradas requieren de una puesta en obra más compleja, mientras que el uso de una mampostería aparejada simplificaría y agilizaría el proceso edilicio, dado que la puesta en obra se puede realizar desde la

12 En esta técnica constructiva, las piedras se colocan alineadas contra el haz interior de las tablas en ambas caras del muro, dejando el interior vacío, que se rellena posteriormente con una mezcla de mortero de cal y piedras más irregulares y pequeñas que las usadas en el exterior, a la manera de un calicanto. Esta masa interior se compacta para que no queden espacios vacíos en el núcleo y tampoco entre las piedras exteriores. Una vez desencofrado se procede al relleno de las juntas y a la aplicación del revestimiento exterior. El uso de dicha técnica constructiva implicaría que la distribución de los mechinales tendría que realizarse de forma homogénea y continua a lo largo de todos los lienzos murarios para el uso regular de agujas, a menudo de pequeña escuadría y no pasantes (Gil 2013: 605-607, 2015). cara superior del propio lienzo que se está construyendo. Se colocarían en primer lugar los mampuestos exteriores aplomados y posteriormente se rellenaría el interior con otras piedras de menor tamaño en hiladas regulares, empleándose también ripios pétreos y cerámicos.

Solo en las esquinas de la torre del homenaje se emplea como elemento de traba y refuerzo la mampostería labrada en forma de sillares con dos caras talladas, habiéndose conservado una parte de la esquina norte. En algunos de los sillares se aprecian marcas de cantería, reconociéndose un total de tres tipos, con letras e inscripciones sencillas. El cercano Molino del Cubo, situado apenas 3,5 km al nordeste de La Peña, fortificado en 1437 por el maestre de la Orden de Calatrava, Luis González de Guzmán, también cuenta con sillares con marcas de cantero en las esquinas y conformando los tabucos ventaneros. Estos sillares presentan una mayor homogeneidad y disposición más regular, mejor traba con las hiladas y labra para diferentes ángulos, por lo que evidencian haber sido talladas para este edificio (García-Pulido 2004). Sin embargo, el empleo de estos sillares en el castillo de La Peña es escaso, el tipo de piedra y sus dimensiones varían y no se realizaron para las jambas de las ventanas de la torre del homenaje. Todo ello parece indicar que los sillares fueron reutilizados, hecho que queda constatado en el empleo como sillares de una lápida funeraria tardo antigua y otra pieza posiblemente de época ibérica.

La cimentación de los muros está ejecutada aprovechando al máximo las condiciones naturales de La Peña, donde los afloramientos rocosos sirven de zócalo y los escarpes llegan a crear farallones naturales infranqueables. A diferencia de las fortificaciones andalusíes, que absorben las irregularidades del terreno por medio de zarpas a modo de plataformas de arranque, el sustrato rocoso sobre el que se levanta la fortaleza Alta de Martos hace directamente de cimentación, sin entalles ni retoques, apoyando los muros directamente sobre la roca, allí donde se aprecian los contactos con el sustrato geológico. Así ocurre en la torre del homenaje, donde se crearon hileras de nivelación y regularización con mampuestos de diferentes tamaños a la manera de un basamento, hasta alcanzar un punto donde el desnivel es regularizado y comienzan las hiladas horizontales del paramento.

El mortero de cal, con árido calizo y arena fue el material utilizado como aglomerante para dar cohesión a los distintos materiales pétreos. En las estructuras conservadas en esta fortaleza se puede constatar la existencia de dos tonalidades distintas en los morteros, a veces presentes incluso en un mismo lienzo. El primer 
aglomerante tiene un aspecto más grisáceo, con una mayor concentración de cal y árido calizo. El segundo tipo es más rojizo, con una dosificación mayor de árido procedente de arenisca e incluso con presencia de chamota.

Aún se conservan muestras de los revocos con los que se cubrirían tanto las dependencias internas como los lienzos de murallas y torres. En los primeros, se utilizó un enlucido más fino, tal y como se puede observar en los paramentos interiores de la torre del homenaje. En cuanto a la muralla, tras el rejuntado entre piedras se aplicó una capa de mortero rico en cal que envolvería y regularizaría todo el lienzo, habiéndose desprendido en buena medida en la cara más externa de los mampuestos, donde la capa aplicada sería más fina. De este modo el paramento presentaría una apariencia bastante lisa y regular que dificultaría la escalada de los muros, sin fingir sillería o un falso despiece pétreo con cordones y fajas de cal en relieve.

Otro material presente en el castillo de La Peña es el ladrillo, utilizado para aparejar las bóvedas. Aunque este material cerámico ha sido objeto sistemático de expolio tras el abandono de la fortaleza, todavía quedan restos de las bóvedas del aljibe, de la torre del homenaje y de la cúpula de la torre circular (T3). Todos los ladrillos tienen unos $28 \mathrm{~cm}$ de soga y en torno a los $4 \mathrm{~cm}$ de espesor, pero la anchura a tizón varía entre los $18 \mathrm{~cm}$ de los conservados en la torre del homenaje y en el aljibe, que son dónde se encuentran las bóvedas de mayores dimensiones, y los $14 \mathrm{~cm}$ de los de la cúpula hemisférica de la torre T3, cuyo menor tamaño se amolda mejor a un contorno circular de algo más de $3 \mathrm{~m}$ de diámetro.

\section{SECUENCIA CONSTRUCTIVA}

Aunque todo el conjunto responde a una técnica constructiva muy homogénea, del estudio de los contactos entre las diferentes estructuras emergentes y del análisis murario, se desprende la existencia de varias fases evolutivas (Figs. 22 y 23).

La primera en ser levantada fue la torre del homenaje, que podría haber servido como un elemento aislado en este primer momento, pues su falta de traba con los lienzos L1 y L9 denotan que se construyó aislada, siendo autosuficiente para permitir una primera ocupación de la cima y para albergar la residencia del comendador de la orden. Se puede apreciar una evolución en la dosificación de los morteros, que presenta una mayor concentración de árido en las partes superiores de esta torre, siendo más ricas en cal las inferiores.
Tras ello, se habría continuado con la construcción del recinto superior, delimitando de esta forma este reducto, que quedaría aislado del resto de la meseta que corona La Peña por medio de un foso. La presencia de la torre T2, que supuestamente habría sido de esquina en este momento, indica una delimitación que debió de ser prioritaria sobre la construcción del resto del recinto, con el propósito de proteger y garantizar la seguridad de la torre principal. De ser así, en esta fase se debió de construir algún elemento para el almacenamiento de agua en este recinto primigenio, en caso de que este no se encontrara en el interior de la torre del homenaje.

Tras esto se levantó todo el recinto amurallado inferior, incluyéndose la torre-puerta $\mathrm{P} 1$, las torres T3, T4 interior y T6, todos los lienzos de murallas y el sistema de abastecimiento de agua con alberca y aljibe. Todos estos elementos se encuentran trabados, pudiéndose apreciar que sus hiladas se entrelazan. De esta forma quedaría definido el contorno fortificado que ha llegado hasta nuestros días. Los morteros empleados en la construcción del recinto inferior presentan una dosificación mayor de cal en comparación con los utilizados en la torre del homenaje. Se aprecian elementos con esquinas redondeadas, como el lienzo L6 y la torre T4 exterior, hecho que puede estar en relación con las mejoras poliorcéticas del siglo XIV ante la artillería, lo que nos permite encuadrar cronológicamente esta parte de la fortaleza en dicha centuria.

La última fase constructiva se contextualiza dentro de reparaciones o actuaciones ejecutadas sobre lo ya edificado, con objeto de mejorar las defensas. El primer ejemplo de refuerzo lo tenemos en la torre T5, entre los lienzos L7 y L8. Se trata de un contrafuerte semicircular que pudo deberse a la necesidad de acortar la distancia del lienzo de muralla. Es posible que se ejecutara justo después de la realización del paño, o incluso a la par que este, puesto que no muestra signos de debilitamiento ni de haber tenido problemas derivados de su longitud. Otro ejemplo de refuerzo lo encontramos en la torre T4, en este caso de una mayor envergadura, revistiéndose con una camisa de mampostería, que sigue la técnica primitiva. Las razones para este refuerzo podrían haber venido motivadas por una reparación de posibles daños tras un ataque o para paliar deficiencias constructivas. Otra posibilidad es que estuviesen relacionadas con el establecimiento de la torre-puerta P2 en este frente murario, conectada con la villa de Martos.

A pesar de disponer de un sistema constructivo sólido y robusto, el paso del tiempo ha mermado considerablemente la envergadura de la fortaleza. El proceso de erosión y desgaste de la fortaleza ha venido motivado 


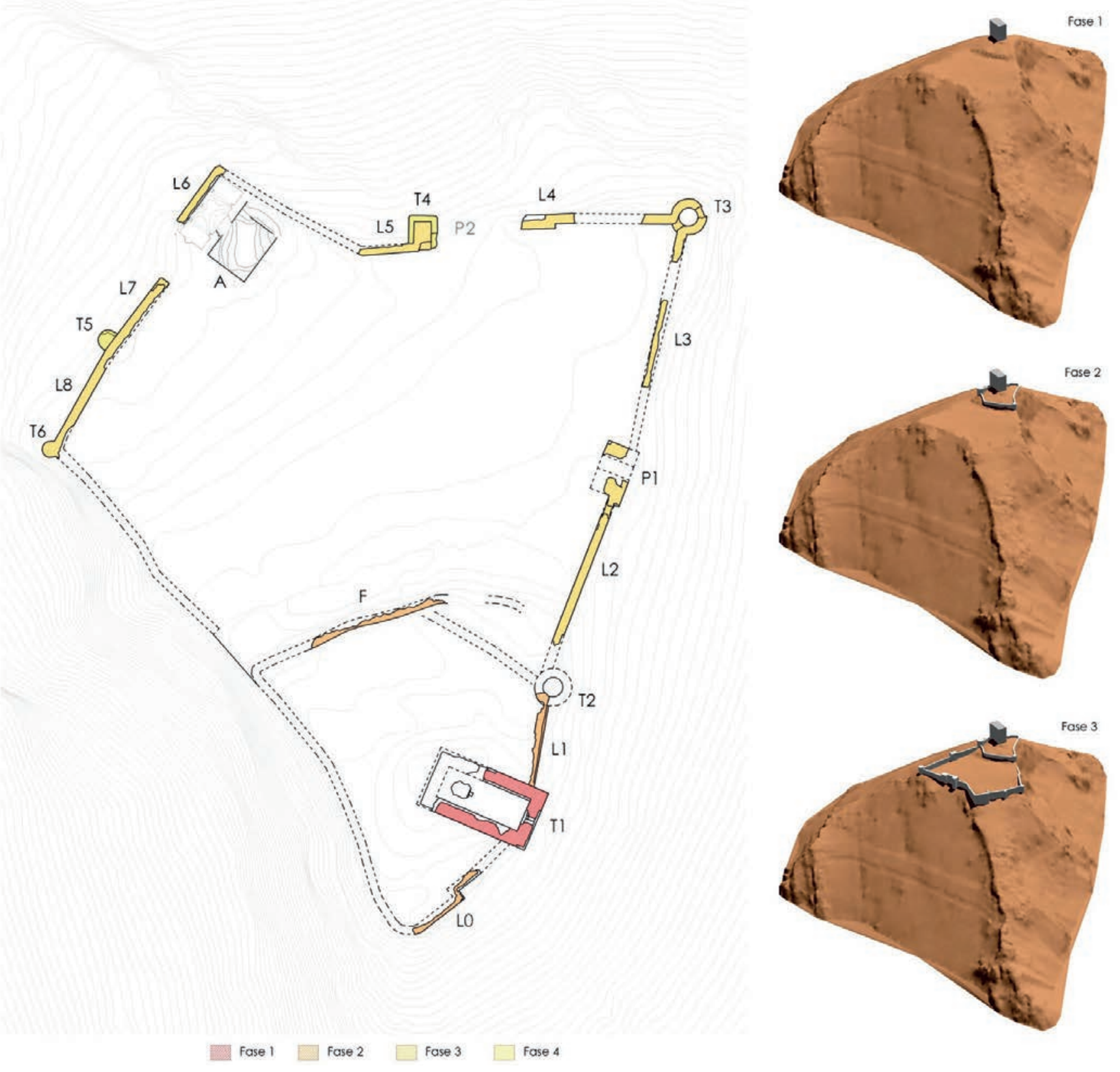

Fig. 22. Principales fases constructivas del castillo edificado por la Orden de Calatrava en La Peña de Martos. Plano y modelización de los autores.

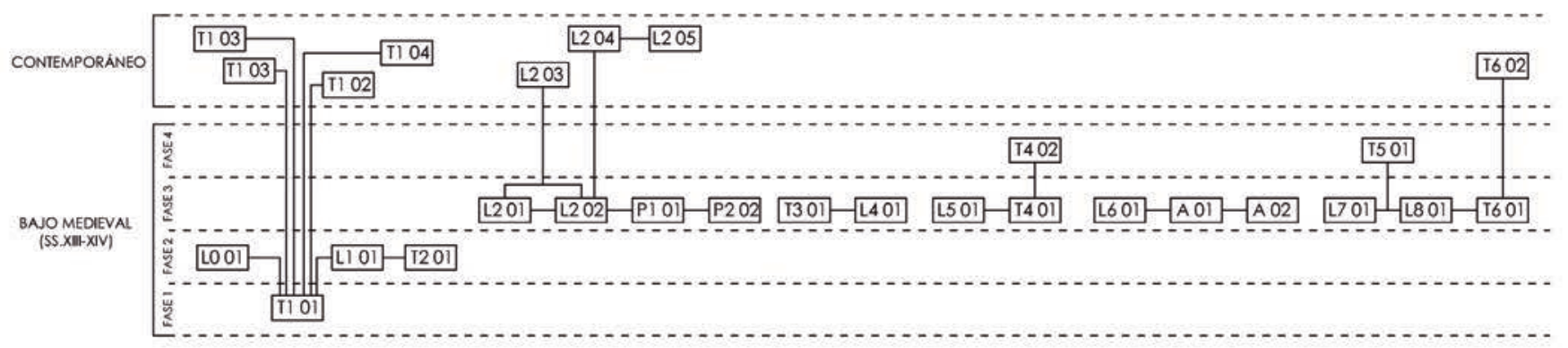

Fig. 23. Representación esquemática de las secuencias constructivas de la fortaleza. Las reseñas contemporáneas tienen que ver con grandes expolios localizados y actuaciones superficiales realizadas sobre los paramentos. Esquema de los autores. 
por dos factores determinantes: la falta de mantenimiento y el expolio. En el análisis murario se puede apreciar el expolio de material, destacando el despojo generalizada del ladrillo, sillares de esquina en la torre del homenaje y otros mampuestos.

\section{CONCLUSIONES}

El estudio murario del castillo de La Peña permite comprobar que la técnica constructiva que fue empleada es bastante uniforme en todo el perímetro. Toda la fortaleza sigue una misma tradición edilicia, sin la aparente reutilización de estructuras previas.

En una primera etapa se habría ejecutado el recinto superior de la fortaleza, que albergó en su interior a la torre del homenaje, levantándose esta al inicio, para posteriormente delimitar el perímetro murario. El hallazgo de los restos de la torre T2 corrobora esta hipótesis, planteándose la posibilidad de la existencia de un sistema de control y acceso en sus inmediaciones.

El estudio de la sección de la torre del homenaje permite analizar su disposición constructiva y su organización interna. Cabe la posibilidad de la existencia de un cuarto nivel, de forma que albergara un aljibe en su base, que de no ser así debió de existir en sus inmediaciones para abastecer de agua a este primer reducto fortificado. Esta torre principal fue reforzada con sillares de esquina de acarreo procedentes de otras construcciones, no pudiéndose atestiguar la presencia de artesanos canteros en el proceso edificatorio.

En el alzado este, el estudio de la torre-puerta P1 muestra la existencia de un cuerpo superior y la posibilidad de que esta contara con algún sistema aspillerado vertical, del que se pudiera hacer uso desde esa parte alta, reforzando de esta manera este punto de entrada al conjunto.

El trazado murario del flanco norte deja varias hipótesis sobre su morfología. La doble cara de mampostería que se aprecia en la torre denota una reparación y descarta la posibilidad de que este refuerzo albergara en su interior una estructura andalusí previa. Se plantea la posibilidad de que entre la torre T5 y el lienzo L4 pudiese haber existido otro acceso a la fortaleza, estando estas estructuras relacionadas con una torre-puerta enmarcada en este frente norte, que permitiría la conexión entre el castillo de La Peña y la fortaleza Baja.

Tras el abandono en el siglo XVI, el recinto quedó desprotegido ante el expolio, acelerando de esta manera el proceso de degradación. Se produjo a partir de entonces la extracción generalizada del ladrillo de las bóvedas. Este hecho podría explicar la degradación que presenta la torre del homenaje, frente a otros casos como la del cercano castillo de Víboras, que se ha conservado casi íntegra hasta el nivel de la terraza, puesto que sus dos bóvedas de cañón se construyeron con lajas de piedra, habiéndose expoliado el ladrillo solo en la rosca del arco de medio punto de su acceso elevado.

Además, en los lienzos del castillo de La Peña hay muestras de la retirada de mampuestos y de los sillares de esquina de la torre del homenaje. En los siglos XVI y XVII la ciudad de Martos experimentó un fuerte desarrollo económico, social y urbanístico, destacando la figura del arquitecto jiennense Francisco del Castillo. Este realizó importantes obras en la villa durante este periodo, como la ampliación y rehabilitación de las iglesias principales, la construcción de la cárcel y el cabildo, o el proyecto de restauración de la fortaleza Baja en 1558, que pretendía valorizar la ciudad medieval. En este contexto de crecimiento urbano, la fortaleza Alta pudo haber servido de cantera, abasteciendo de ladrillos y de mampuestos a las obras marteñas.

La torre del homenaje del castillo de la Peña presenta un delicado estado de conservación. Al menos debe de conservar una bóveda casi completa por debajo de la rasante actual, que podría corresponder con la del nivel de la entrada elevada a la torre. El paramento más occidental está desaparecido a partir de dicho nivel, hecho que también ha afectado a las esquinas oeste y norte, así como a una porción de los lienzos sur y norte. La meridional se conserva a duras penas, una vez han sido expoliados todos sus sillares, frente a la septentrional, que los conserva en gran medida. Muchos de los paramentos están descarnados, al haber perdido la cara de mampostería encofrada siguiendo hiladas enripiadas $^{13}$. Con todo, esta muestra de la arquitectura medieval cristiana de aparato continúa siendo bien reconocible en muchas de sus partes constitutivas.

\section{BIBLIOGRAFÍA}

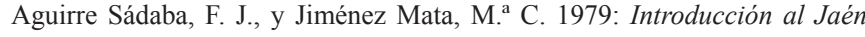
islámico. Instituto de Estudios Giennenses, Jaén.

Almagro Gorbea, A. y Orihuela Uzal, A. 2013: "Bóvedas nazaríes construidas sin cimbra: Un ejemplo en el Cuarto Real de Santo Domingo (Granada)", en S. Huerta y F. López Ulloa (eds.), Actas del Octavo Congreso

13 En el transcurso de la investigación sobre esta torre se ha podido constatar que el proceso de deterioro ha aumentado, agrandándose las roturas e incrementándose la pérdida de mampuestos. 
Nacional de Historia de la Construcción, pp. 25-34. Instituto Juan de Herrera (Escuela Técnica Superior de Arquitectura de Madrid), Madrid.

Ansón Oliart, F. 1998: Fernando III. Rey de Castilla y León. Ediciones Palabra, Madrid.

Aranda Palacios, Á., Segovia Fernández, A., Claros Bastante, C. y Martín Prado, P. 2016: "De fortalezas islámicas a castillos calatravos", en I. J. Gil Crespo (ed.), Actas de las Segundas Jornadas sobre Historia, arquitectura y construcción fortificada, pp. 45-62. Instituto Juan de Herrera (Escuela Técnica Superior de Arquitectura de Madrid), Fundación Cárdenas, Centro de Estudios José Joaquín de Mora, Madrid.

Bonilla Martos, A. L. 2013: "Las villas romanas en la economía de la Colonia Augusta Gemella Tuccitana. Protección legal de los restos arqueológicos y su uso como recurso didáctico", Trastámara, revista de Ciencias Auxiliares de la Historia, 11.2, pp. 33-75.

Burgos Núñez, A. 1998: "Una aproximación a los castillos de Martos", Aldaba, 5, pp. 37-45.

Cano Carrillo, J. y Serrano Peña, J. L. 2009: "Algunos apuntes sobre la intervención arqueológica de apoyo a la rehabilitación de la Torre Almedina en Martos", Aldaba, 26, pp. 67-81.

Capel Margarito, M. C. 1994: "Martos en la historia y en las artes". Boletín del Instituto de Estudios Giennenses, 153, pp. 417-434.

Castillo Armenteros, J. C. y Alcázar Hernández, E. M. 2006: "La Campiña del alto Guadalquivir en la Baja Edad Media. La dinámica de un espacio fronterizo", Studia Historica: Historia Medieval, 24, pp. 155-196.

Castillo Armenteros, J. C. y Castillo Armenteros, J. L. 2003: "La organización militar de la Orden de Calatrava en el Alto Guadalquivir a través de las investigaciones arqueológicas", Arqueología y territorio medieval, 10.2, pp. 181-231.

Castillo Armenteros, J. C., Salvatierra Cuenca, V., Navarro Pérez, M. y Gutiérrez Calderón, M. ${ }^{a}$ V. 2013: "Las fortalezas de la Orden de Calatrava en el sector occidental de la provincia de Jaén", en I. C. F. Fernandes (ed.), Castelos das Ordens Militares, pp. 193-227. Direçao-General do Patrimonio Cultura, Secretário de Estado da Cultura, Governo de Portugal, Lisboa.

Cerezo Moreno, F. y Eslava Galán, J. 1989: Castillos y atalayas del Reino de Jaén: Nuevo álbum de dibujos. Riquelme y Vargas, Jaén.

Chalmeta Gendrón, P. 2003: Invasión e islamización. La sumisión de Hispania y la formación de al-Andalus. Universidad de Jaén. Servicio de Publicaciones, Jaén.

Cressier, P. y Salvatierra Cuenca, V. 2014: Las Navas de Tolosa 1212-2012: miradas cruzadas. Universidad de Jaén, Jaén.

Eslava Galán, J. 1984: Materiales y técnicas constructivas en la fortificación bajomedieval. Universidad de Granada, Granada.

Eslava Galán, J. 1990: "El castillo de la Peña de Martos y la Orden de Calatrava", Boletín del Instituto de Estudios Giennenses, 142, pp. 149-160.

Gallego Valle, D., Molero García, J. M.a , Castilla Pascual, F. J., Peña Ruiz, C. y Sanz Martínez, D. 2016: "El uso del tapial en las fortificaciones medievales de Castilla-La Mancha: propuesta de estudio y primeros resultados de la investigación", en I. J. Gil Crespo (ed.), Actas de las Segundas Jornadas sobre Historia, arquitectura y construcción fortificada, pp. 45-62. Instituto Juan de Herrera (Escuela Técnica Superior de Arquitectura de Madrid), Fundación Cárdenas, Centro de Estudios José Joaquín de Mora, Madrid.

García Fernández, M. 1987: "La frontera de Granada a mediados del siglo XIV", Revista de estudios andaluces, 9, pp. 69-86.

García-Pulido, L. J. 2004. "El sistema fortificado del Molino del Cubo (Torredonjimeno, Jaén)", Castillos de España, 132, pp. 23-33.

García-Pulido, L. J., Caballero Cobos, A., Ramírez Ayas, M. y Brazille Naulet, V. 2016. "Primeros resultados del proyecto de conservación y puesta en valor de las estructuras arqueológicas del Cerro del Castillo de Montejícar (Granada)", en I. J. Gil Crespo (ed.), Actas de las Segundas Jornadas sobre Historia, arquitectura y construcción fortificada, pp. 255-286. Instituto Juan de Herrera (Escuela Técnica Superior de Arquitectura de Madrid), Fundación Cárdenas, Centro de Estudios José Joaquín de Mora, Madrid.

García-Pulido, L. J., Pecete Serrano, S. M. y Buendía Moreno, A. F. 2016. "Nuevos datos sobre la torre de Agicampe (Loja, Granada)", en I. J. Gil Crespo (ed.), Actas de las Segundas Jornadas sobre Historia, arquitectura y construcción fortificada, pp. 287-306. Instituto Juan de Herrera (Escuela Técnica Superior de Arquitectura de Madrid), Fundación Cárdenas, Centro de Estudios José Joaquín de Mora, Madrid.

Gil Crespo, I. J. 2013: Fundamentos constructivos de las fortificaciones fronterizas entre las coronas de Castilla y Aragón de los siglos XII al XV en la actual provincia de Soria. Tesis Doctoral. E.T.S. Arquitectura de la Universidad Politécnica de Madrid.

Gil Crespo, I. J. 2015: Fundamentos constructivos de las fortificaciones fronterizas entre las coronas de Castilla y Aragón de los siglos XII al XV en la actual provincia de Soria. Colección Premios Defensa, Ministerio de Defensa, Madrid.

Gómez de Terreros Guardiola, M. ${ }^{a}$ V. 2010: La arquitectura de las órdenes Militares en Andalucía. Conservación y restauración. Universidad de Huelva, Servicio de publicaciones, Huelva.

González González, J. 1980: Reinado y diplomas de Fernando III. Tomo I. Monte de Piedad y Caja de Ahorros de Córdoba, Córdoba.

Gutiérrez Pérez, J. C. 2009a: "Los orígenes de la Encomienda Calatrava de La Peña de Martos". Martos y su comarca en la Baja Edad Media. Ayto. de Martos, Martos.

Gutiérrez Pérez, J. C. 2009b: "La Encomienda de La Peña de Martos y su organización defensiva en el siglo XIII". Aldaba, 26, pp. 17-22.

Gutiérrez Pérez, J. C. 2011: "El asedio de Martos por el Rey al-Ahmar y la defensa de la condesa de Aurembiaix de Urgel. Mito o realidad", en VIII Estudios de Frontera. Mujeres y frontera, pp. 187-193. Diputación Provincial de Jaén, Jaén.

Gutiérrez Pérez, J. C. 2013: "La organización administrativa del territorio islámico en el suroeste de la provincia de Jaén (ss. X-XII): el iqlim de Martus (Martos)", Aldaba, 33, pp. 11-16.

López Molina, M. 1983: "Tucci, etapa ibérica de la historia de Martos", Boletín del Instituto de Estudios Giennenses, 116, pp. 71-94.

López Molina, M. 2003: "Armas y bienes muebles de la Fortaleza de La Peña de Martos en 1557”, Aldaba, 15, pp. 29-31.

Luna Collantes, M. B., Serrano Peña J. L., Cano Carrillo, J. 2004: "Prospección arqueológica superficial con recogida de material y limpieza en la peña de Martos (Jaén)", Anuario Arqueológico de Andalucía, 2004.1, pp. 2006-2011.

Madoz e Ibáñez, P. 1848: Diccionario Geográfico-Estadístico-Histórico de España y sus Posesiones de Ultramar, Tomo XI. Imprenta del Diccionario Geográfico, a cargo de D. José Rojas, Madrid.

Menéndez Pidal, R. (ed.) 1977: Primera Crónica General de España. Tomo II ( $3^{\mathrm{a}}$ reimp.). Cátedra Seminario Menéndez Pidal-Editorial Gredos S.A., Madrid.

Molina Molina, A. L. y Eiroa Rodríguez, J. A. 2009: El castillo medieval en tiempos de Alfonso X el Sabio. Servicio de Publicaciones de la Universidad de Murcia, Murcia.

Olivares Barragán, F. 1992: Castillos de la Provincia de Jaén. Excma. Diputación de Jaén, Jaén.

Orihuela Uzal, A. y Castillo-Martínez, J. M. 2012: "Restoration of the Andalusí wall of the Alcazaba Antigua of Granada", en C. Mileto, F. Vegas López-Manzanares y V. Cristini (coords.), Rammed Earth Conservation: Proceedings of the first International Conference on Rammed Earth Conservation, Restapia 2012, pp. 401-406. Valencia.

Ponz Piquer, A. 1791: Viaje de España en el que se da noticia de las cosas mas apreciables y dignas de saberse que hay en ella. Imprenta de la viuda de don Joaquín Ibarra. Madrid.

Quesada-García, S. y Fernández Ruiz, R. 1991: Martos: informe-diagnóstico del conjunto histórico. Consejería de Obras Públicas y Transportes, Junta de Andalucía, Sevilla.

Recio Veganzones, A. y López Delgado, R. 2002: “La fortaleza Baja de Martos y su Castillo, y los primeros proyectos de su reconstrucción". Aldaba, 12 , pp. 69-84.

Ruiz Fúnez, F. L. 2010: La Encomienda de Martos de la Orden de Calatrava (siglos XIII-XV). Ayto. de Martos, Martos.

Valdecantos Dema, R. 1998: Castillos de Jaén. El Olivo, León.

Villalta, D. de 1982 [1579]: Historia de la Antigüedad y fundación de la Peña de Martos. Asociación Artística y Cultural TUCCI, Jaén. 